\title{
The impact of droughts and water management on various hydrological systems in the headwaters of the Tagus River (central Spain)
}

\author{
Lorenzo-Lacruz, J. ${ }^{1}$, Vicente-Serrano, S.M. ${ }^{1 *}$, López-Moreno, J.I. ${ }^{1}$, Beguería, S. ${ }^{2}$, García-Ruiz, \\ J.M. ${ }^{1}$, Cuadrat, J.M. ${ }^{3}$ \\ 1. Instituto Pirenaico de Ecología, CSIC (Spanish Research Council), Campus de Aula Dei, P.O. Box 202, Zaragoza \\ 50080, Spain \\ 2. Estación Experimental de Aula Dei, CSIC (Spanish Research Council), Zaragoza, Spain \\ 3. Departamento de Geografía. Universidad de Zaragoza, Zaragoza, Spain. \\ * corresponding author: svicen@ipe.csic.es
}

Abstract. The influence of climate variation on the availability of water resources was analyzed in the headwaters of the Tagus River basin using two drought indices, the standardized precipitation index (SPI) and the standardized precipitation evapotranspiration index (SPEI). This basin is highly regulated and strategic, and contains two hyperannual reservoirs that are the origin of the water supply system for Mediterranean areas of southeast Spain. The indices confirmed that drought conditions have prevailed in the headwaters of the Tagus River since the 1970s. The responses in river discharge and reservoir storage were slightly higher when based on the SPEI rather than the SPI, which indicates that although precipitation had a major role in explaining temporal variability in the analyzed parameters, the influence of temperature was not negligible. Moreover, the greatest response in hydrological variables was evident over longer timescales of the climatic drought indices. Although the effect of climate variability on water resources was substantial during the analyzed period, we also showed a major change in hydrological-climatic relationships in regulated systems including reservoir storage and outflow. These were closely related to changes in external demand following commencement of the water transfer system to the Júcar and Segura basins after the 1980s. The marked reduction in water availability in the basin, which is related to more frequent droughts, contrasts with the amount of water transferred, which shows a clear upward trend associated with increasing water demand in the Mediterranean basin. 
Keywords: drought, global warming, standardized precipitation index, standardized precipitation evapotranspiration index, water transfer, reservoir management, Tagus River, Spain.

\section{Introduction}

An effect of global change on environmental conditions in the western Mediterranean region is increasing uncertainty in water resource availability (García-Ruiz et al., 2009). The projections of climate models are for a general decrease in precipitation and increasing temperatures in the region (Giorgi and Lionelo, 2008), which may markedly reduce river flows (e.g., Kilsby et al., 2007). Nevertheless, there are various sources of uncertainty in climate change simulations (Räisanen, 2007), and difficulties are associated with establishment of direct relationships between climate variability and water resources, as a consequence of the substantial influence of land cover (Llorens et al., 1995; Beguería et al., 2003; García-Ruiz et al., 2008) and water management strategies (López-Moreno et al., 2007) on the response of river flows to climate variability. Analysis of the temporal evolution of water resources in the Mediterranean area is complex, given the large natural climate variability of the region (Vicente-Serrano and Cuadrat, 2007; López-Bustins et al., 2008; De Luís et al., 2009), land cover changes in headwaters (Vicente-Serrano et al., 2004; Lasanta et al., 2005; MacDonald et al., 2000; Sluiter and De Jong, 2007), and the intense water regulation necessary to meet high urban and agricultural demand (Batalla et al., 2004; López-Moreno et al., 2009). To understand the possible consequences of climate change processes on the future availability of water resources in the region, it is necessary to determine the current relationship between climate variability and water resources, taking account of different hydrological subsystems (e.g., river discharge, reservoir storage) and the major role of dam and canal operations in the regulation of river flows.

In the western Mediterranean region the availability of water resources is critical during certain periods. River flows show strong seasonality characterized by low natural flow in summer; 
management of reservoirs is thus focused on meeting urban and irrigation demands during this season (Maneux et al., 2001; Snoussi et al., 2002). The high frequency of droughts in the area makes it necessary to improve management strategies during dry periods. To this end it is important to determine the empirical relationship between climatic and hydrological droughts, which will enable accurate assessment of the possible impact of environmental change processes.

Isolating the influence of climate is difficult because the response of hydrological systems to precipitation can vary markedly as a function of time (Changnon and Easterling, 1989; Elfatih et al., 1999; Pandey and Ramasastri, 2001), as a result of temporal differences in the frequencies of hydrological and climatic variables (Skøien et al., 2003). In a study in the central Spanish Pyrenees, Vicente-Serrano and López-Moreno (2005) showed very different timescale responses to precipitation accumulation between river discharge (short timescale) and reservoir storage (long timescale). A similar pattern was found by Szalai and colleagues (2000) in Hungary. In Greece, Vasiliades and Loukas (2009) reported different response times for soil moisture and river discharge to two Palmer drought indices, with variations in soil moisture occurring at higher frequency than river discharge. This was more marked for groundwater level, which responds to precipitation only following long-term accumulation (Khan et al., 2008). Thus, the effect of climatic droughts on groundwater shows distinct temporal inertia (Peters et al., 2005).

Reservoir regulation and water transfer disrupt climate-hydrology relationships, sometimes dramatically, making it difficult to determine the role of precipitation variability on availability of water resources. In addition, several studies have shown that recent temperature increases (Jones and Moberg, 2003) are having a negative effect on the availability of water resources, as a consequence of water losses caused by evapotranspiration (Nicholls, 2004; Cai and Cowan, 2008;

4 Gerten et al., 2008). To date, no studies have analyzed this issue in the western Mediterranean region. 
Few empirical analyses have related hydrological records to climate indices, or tested the usefulness of various drought indices for monitoring water resources in different systems. The main objective of this study was to determine the relationship between two different multi-scalar drought indices (the standardized precipitation index, SPI; and the standardized precipitation evapotranspiration index, SPEI) and three hydrological variables (river discharge, reservoir storage, and reservoir release) in the headwaters of the Tagus River. This is a highly regulated and strategic basin that has two hyperannual reservoirs (i.e., where the storage capacity exceeds the annual discharge from a regulated river) that are the origin of a water transfer system supplying the Mediterranean areas of southeast Spain. Additional objectives of the study were i) to identify the best drought index and timescale for monitoring water resources in the different subsystems, and, ii) to assess the influence of water management and warming processes on temporal changes in climate-hydrological relationships.

\section{Study area}

Water resources are intensively regulated in the Alto Tajo region, which comprises the headwaters of the Tagus River, between the Iberian Range and the Plateau of Castille. The river basin is in a mountainous area ranging in altitude from $600 \mathrm{~m}$ at the Bolarque reservoir to 1,935 $\mathrm{m}$ at the eastern extremity of the basin, and has a surface area of $7,417 \mathrm{~km}^{2}$. The relief is dominated by moorlands, the main structural unit, which descend gradually over a limestone base from the foot of the Orihuela and Albarracín ranges. Below 1,000 m a marl substrate is evident, and the valley opens up and provides a suitable area for the retention of water.

The spatial distribution of precipitation follows a topographic pattern. Mean annual precipitation decreases from 1,000 mm in the Albarracín Range (east) to about $500 \mathrm{~mm}$ in low-altitude areas. Precipitation is strongly seasonal, with a peak in May and another in November; the area is also subject to the low summer rainfall typical of the Mediterranean region. Temperatures are 
112 characterized by extremes and oscillations given the continental nature of the climate. The 113 maximum daily oscillation, $29.4^{\circ} \mathrm{C}$, was recorded in 1981 . The mean annual temperature is less than $11410^{\circ} \mathrm{C}$ for most of the basin, but during winter the average temperature drops to $1-3^{\circ} \mathrm{C}$, making it one 115 of the coldest regions on the Iberian Peninsula. In the hottest month (July) the average temperature 116 is $21.9^{\circ} \mathrm{C}$.

117 The area has a dense hydrological network divided into two main components, the Tagus and 118 Guadiela rivers, whose waters are collected and regulated downstream (Figure 1). The water is 119 controlled to supply various water uses in the region, and to transfer water to the Mediterranean 120 coastlands. The basin has two large reservoirs, the Entrepeñas and Buendía dams. The Entrepeñas 121 has a capacity of $802 \mathrm{hm}^{3}$ and the wall height of the dam is $87 \mathrm{~m}$; it was built in 1956 to collect the 122 waters of the Tagus River. The Buendía dam stores the waters of the Guadiela, Mayor, and 123 Guadamejud rivers. The dam was built in 1957, the wall height of the dam is $78 \mathrm{~m}$, and has a 124 maximum storage capacity of $1,638 \mathrm{hm}^{3}$. Both reservoirs act as a single storage unit, as they are 125 connected by a tunnel. The Bolarque Dam is located downstream of the discharge of the two main 126 dams, at the convergence of the Tagus and Guadiela rivers. The dam was built in 1910, but underwent several modifications that were not finalized until 1951. The main function of the dam is 128 distribution of the water collected upstream in the Entrepeñas and Buendía dams; some is sent to the 129 Tajo-Segura water transfer and the Bolarque-Jarama irrigation supply systems, and the remainder 130 flows a few kilometers down the main stream of the Tagus River to the Zorita reservoir, which was 131 built in 1947 for hydroelectric production.

132 Two principal land cover types exist in the study area: Above $1000 \mathrm{~m}$ the predominant land cover 133 are the forests, composed mainly by conifers, which occupy $42.5 \%$ of the study area. Dry-farmed 134 cropland covers $43.9 \%$ of the surface, mainly in the flat areas. Other important land cover types in 135 the study area are thicket (9.9\%) and grasslands (2.3\%). Irrigated lands, urban areas and agro136 forestry occupy percentages lower than $1 \%$ of the study area. 
The area is highly strategic in terms of water resources, as it provides water to the Tajo-Segura

138 Transfer. The diversion of water to the Mediterranean region involves political decisions at a 139 national level, and has been the focus of territorial conflicts, especially during drought periods 140 (Garrote et al., 2007).

\section{1} 142 143 144 145 146

\section{Dataset and methodology}

\subsection{Climate data}

Data on monthly precipitation, and maximum and minimum temperatures between 1961 and 2006 were provided by the Spanish Meteorological Agency (AEMET). This consisted of 64 monthly temperature series and 147 monthly precipitation series within the study area and neighboring zones. The availability and quality of the series were variable; both precipitation and temperature series contained numerous discontinuities, and long continuous series were very rare. Therefore, for further analysis we selected only those series with $<10 \%$ gaps ( 9 precipitation series and 3 temperature series; see Fig. 1). Gaps were filled using multiple linear regressions.

Among the different existing techniques to detect and adjust the temporal non-homogeneities of climate series, (see reviews in Peterson et al., 1998 and Beaulieu et al., 2007), we have used the standard normal homogeneity test (SNHT; Alexandersson, 1986), which is widely used to homogenize temperature and precipitation series in different regions (e.g. Alexandersson and Moberg, 1997; Begert and Schlegel, 2005). Following Peterson and Easterling (1994), a relative homogenization procedure was applied using reference series incorporating the three most correlated series for precipitation and the two most correlated for temperature. The ANCLIM program (Stepánek, 2004) was used to perform the homogenization process. Using the precipitation and temperature series for the different stations we created a precipitation and mean temperature 
and López-Moreno, 2005). The weight of each series was determined from the surface area represented by each station, calculated using Thiessen polygons (Jones and Hulme, 1996).

\subsection{Hydrological records}

Hydrological data for 1961-2006 were provided by the Tagus Water Authority (Confederación Hidrográfica del Tajo). Four parameters were considered in the analysis:

i) the monthly river discharges at three gauging stations (Fig. 1) that had no data gaps for the 1961-2006 period;

ii) inflows to the interconnected Entrepeñas and Buendía reservoir system;

iii) the total storage registered in both reservoirs; and

iv) the net outflows to the Tagus River below the Bolarque and Zorita reservoirs, located immediately downstream of the Entrepeñas and Buendía reservoir system.

Among the used hydrological parameters, only the river discharges and inflows to the reservoirs system are natural non-human managed resources. Nevertheless, the analysis of the hydrological response to climate can not be restricted to the natural non-human affected systems. In addition to different human interferences, in the Tagus basin climate variability also controls reservoir storages and releases downstream the dams (López-Moreno et al., 2007). Thus, assessing the connection between climate variability and human inference is of great interest, as most of the water supplied to urban settlements, agriculture and industry depends from highly regulated fluvial stretches.

\subsection{Hydrological drought index calculation}

The various approaches to analyzing hydrological droughts are commonly based on discharge thresholds (Tallaksen et al., 1997; Fleig et al., 2006). This enables the identification of low discharge periods, but does not take into account the seasonality of discharges, which usually leads to naturally low summer flows being classified as low flow periods. This is a particular problem in highly seasonal regimes, including the Mediterranean rivers. We quantified hydrological drought 
conditions by relating monthly discharge anomalies to average conditions, following Dracup et al. (1980). For this purpose we followed the approach commonly used for climatic drought index calculations: namely the corresponding number of standard deviations relative to average values. This approach has been used by Zaidman et al. (2001), Shukla and Wood (2008) and LópezMoreno et al., (2009), among others.

As hydrological records are highly biased and do not commonly follow a normal distribution, it was necessary to standardize the probability distribution of the hydrological records. A comparison was made among several skewed probability distributions, based on an $\mathrm{L}$ moment ratio diagram (Greenwood et al., 1979; Hosking, 1990). The resulting plot enabled comparison of empirical parameters obtained from inflows, reservoir storages and releases, with parametric theoretical distributions. The L-moments ratio diagram (Fig. 2) shows the empirical values of L-skewness and L-kurtosis for monthly series of river flows, inflows to the Entrepeñas-Buendía system, reservoir storages, and outflows to the Tagus River, along with theoretical curves for some parametric distributions. López-Moreno et al. (2009) showed the effectiveness of the Pearson III distribution for obtaining a hydrological drought index in the lower part of the Tagus basin. Zaidmann et al. (2001) used a lognormal distribution in north and central Europe. For the United States of America, Shukla and Wood (2008) showed a generally good performance with the 2-parameters gamma and lognormal distributions, but also showed that the 3-parameters lognormal and the generalized extreme value distributions were also applicable over widely varying hydroclimatic regimes. In the headwaters of the Tagus River, we showed large differences among the variables analyzed. River flows and inflows to the Entrepeñas and Buendía system showed high dispersion but, in general the Pearson III and the lognormal distribution were suitable for modeling the data. High dispersion was also found for the monthly series of outflows as a function of the monthly series. After several attempts we selected the Pearson III distribution to obtain an outflow drought index. The reservoir storages did not show dispersion, showing the different monthly series an adjustment to the 
217 Generalized Pareto distribution, which was used to calculate a reservoir drought index. The 218 confirmation step, using the Kolmogorov-Smirnov test, allowed selection of the Generalized Pareto 219 distribution for the different monthly series of reservoir storages, and the Pearson III distribution for 220 inflows and outflows.

221 The L-moments procedure was used to obtain the parameters of the Pearson III and Generalized 222 Pareto distributions. The L-coefficients of skewness and kurtosis, $\tau_{3}$ and $\tau_{4}$ respectively, were 223 calculated as follows:

$224 \tau_{3}=\frac{\lambda_{3}}{\lambda_{2}}$

$225 \tau_{4}=\frac{\lambda_{4}}{\lambda_{2}}$

226 where $\lambda_{2}, \lambda_{3}$ and $\lambda_{4}$ are the L-moments of the precipitation series. These were obtained from 227 probability-weighted moments (PWMs), using the formulae:

$228 \quad \lambda_{1}=\alpha_{0}$

$229 \lambda_{2}=\alpha_{0}-2 \alpha_{1}$

$230 \quad \lambda_{3}=\alpha_{0}-6 \alpha_{1}+6 \alpha_{2}$

$231 \quad \lambda_{4}=\alpha_{0}-12 \alpha_{1}+30 \alpha_{2}-20 \alpha_{3}$

232 The PWMs of order $s$ were calculated as:

$233 \quad \alpha_{s}=\frac{1}{N} \sum_{i=1}^{N}\left(1-F_{i}\right)^{s} X_{i}$

234 where $x_{i}$ is the data from a given precipitation series and $F_{i}$ is the frequency estimator. $F_{i}$ was 235 calculated following the approach of Hosking (1990):

$236 \quad F_{i}=\frac{i-0.35}{N}$ 
237 where $i$ is the range of observations arranged in increasing order, and $\mathrm{N}$ is the number of data 238 points. According to the Pearson III distribution, the probability distribution function of $x$ is given 239 by:

$240 \quad F(x)=\frac{1}{\alpha \Gamma(\beta)} \int_{\gamma}^{x}\left(\frac{x-\gamma}{\alpha}\right)^{\beta-1} e^{-\left(\frac{x-\gamma}{\alpha}\right)}$

241 The probability distribution function of $x$, according to the Generalized Pareto distribution, is given 242 by

$243 \quad F(x)=1-\left[1-\frac{\kappa}{\alpha}(x-\varepsilon)\right]^{1 / \kappa}$

244 The parameters of the Pearson III distribution were obtained following Hosking (1990):

245 If $\tau_{3} \geq 1 / 3$ then $\tau_{\mathrm{m}}=1-\tau_{3}$, and $\beta$ can be obtained using the expression:

$246 \quad \beta=\frac{\left(0.36067 \tau_{m}-0.5967 \tau^{2}{ }_{m}+0.25361 \tau^{3}{ }_{m}\right)}{\left(1-2.78861 \tau_{m}+2.56096 \tau^{2}{ }_{m}-0.77045 \tau^{3}{ }_{m}\right)}$

247 If $\tau_{3}<1 / 3$ then $\tau_{\mathrm{m}}=3 \pi \tau^{2}$, then $\beta$ can be obtained using the expression:

248

$\beta=\frac{\left(1+0.2906 \tau_{m}\right)}{\left(\tau_{m}+0.1882 \tau_{m}^{2}+0.0442 \tau_{m}^{3}\right)}$

$249 \quad \alpha=\sqrt{\pi} \lambda_{2} \frac{\Gamma(\beta)}{\Gamma(\beta+1 / 2)}$

$250 \gamma=\lambda_{1}-\alpha \beta$

251 The parameters of the Generalized Pareto distribution were also obtained according to Hosking 252 (1990) using L-moments:

253

$\alpha=\lambda_{1}\left(\frac{1}{\tau_{2}}-1\right)$

$254 \kappa=\frac{1}{\tau_{2}}-2$

$\varepsilon=\lambda_{1}-\lambda_{1}(2+\kappa)$ 
The $\mathrm{F}(\mathrm{x})$ values obtained were converted to $\mathrm{z}$-standardized values. For example, following the classical approximation of Abramowitz and Stegun (1965):

258

$z=W-\frac{C_{0}+C_{1} W+C_{2} W^{2}}{1+d_{1} W+d_{2} W^{2}+d_{3} W^{3}}$,

259

where

$W=\sqrt{-2 \ln (P)}$ for $P \leq 0.5$,

where $P$ is the probability of exceeding a determined $D$ value, $P=1-F(x)$. If $P>0.5, P$ is replaced

by $1-P$, the sign of the resultant $\mathrm{z}$-value is reversed. The constants are: $C_{0}=2.515517, C_{1}=$

0.802853, $C_{2}=0.010328, d_{1}=1.432788, d_{2}=0.189269, d_{3}=0.001308$. The average value of the

hydrological index is 0 , and the standard deviation is 1 .

Figure 3 shows the evolution of the three hydrological drought indices, for which marked differences were evident. The inflows to the Entrepeñas-Buendía system had higher temporal frequency than the reservoir storages. The outflows behaved very differently before and after the 1980s, with positive values dominating prior to this period, and very negative outflow values dominating in the following two decades.

\subsection{Calculation of climatic drought indices}

From regional series of monthly precipitation and temperature we obtained two multi-scalar climate drought indices: the standard precipitation index (SPI) (McKee et al., 1993) and the standardized precipitation evapotranspiration index (SPEI) (Vicente-Serrano et al., 2009). It is commonly assumed that drought is a multi-scalar phenomenon (McKee et al., 1995). This is very important for drought quantification and monitoring, as the time scale over which precipitation deficits accumulate functionally separates different types of drought, and enables quantification of the natural lags between precipitation and other usable water sources, such as river discharges and water storages (Changnon and Easterling, 1989; Elfatih et al., 1999; Pandey and Ramasastri, 2001); there are with several empirical lines of evidence for this lag (Szalai et al., 2000; Sims et al., 2002; 
Vicente-Serrano and López-Moreno, 2005; Patel et al., 2007; Khan et al., 2008). For this reason we considered a diversity of time scales for both drought indices (1-48 months). The justification for using two different drought indices is the fact that the SPI only accounts for precipitation effects, whereas the SPEI accounts for inputs (precipitation) and outputs (evapotranspiration) to the system. Although precipitation is the main variable explaining the frequency, duration and severity of droughts (Chang and Cleopa, 1991; Heim, 2002), recent studies have shown that the effect of temperature (or evapotranspiration) is significant (Hu and Willson, 2000), particularly under global warming scenarios (Dubrovsky et al., 2008). Abramopoulos et al. (1988) showed that evaporation and transpiration can consume up to $80 \%$ of rainfall, and found that the efficiency of drying due to temperature anomalies is as high as that due to rainfall shortage. Syed et al. (2008) showed that precipitation dominates terrestrial water storage variation in the tropics, but evapotranspiration explains the variability at middle latitudes. In addition, studies have shown that anomalous high temperatures related to warming processes have in recent years exacerbated the impact of climatic droughts on water resources (Nicholls, 2004; Cai and Cowan, 2008).

The SPI is calculated by adjusting the precipitation series to a given probability distribution. 297 Initially, the Gamma distribution was used to calculate the SPI (McKee et al., 1993), but the 298 Pearson III distribution is more robust, given its three parameters (Vicente-Serrano, 2006). The 299 complete formulation of the SPI following the Pearson III distribution and the L-moments method 300 for calculating parameters is described in Vicente-Serrano (2006), and López-Moreno and Vicente301 Serrano (2008). A C++ program developed by the Spanish Scientific Research Council (CSIC) 302 (http://digital.csic.es/handle/10261/10006) was used for this purpose.

303 The SPEI is based on a monthly climatic water balance (precipitation minus potential 304 evapotranspiration), which is adjusted using a 3-parameter log-logistic distribution to take into 305 account common negative values. The values are accumulated to different time scales, following a 306 similar approach to that for the SPI, and converted to standard deviations with respect to average 
values. The complete methodology is described by Vicente-Serrano et al. (2009); a C++ program, 308 also developed by the CSIC (http://digital.csic.es/handle/10261/10002), was used for calculations.

\subsection{Statistical analysis}

Hydrological and climatic drought indices were related using the parametric Pearson coefficient of correlation to measure the degree of association between hydrological and climatic droughts. The different time scales of the SPI and the SPEI were included in the analysis to determine the best time scale and climatic drought index for explaining hydrological variability. Analyses were based on complete continuous series, but also separately for the 12 monthly series of standardized inflows, reservoir storages and outflows.

To determine possible changes in the relationship between climatic and hydrological droughts we undertook the same analyses using moving window correlations (15 years). This enabled assessment of whether climatic-hydrological drought relationships are stable or not, and possible interferences in terms of the management of water resources. The non-parametric Spearman's rho correlation coefficient (Siegel and Castelan, 1988) was applied to a moving window Pearson R correlation series to detect significant trends in the climate-hydrological drought relationships in various months of the year.

A flow chart summarizing all steps of the methodology applied is shown in Fig. 4.

\section{Results}

\subsection{Evolution of climatic droughts}

Figure 5 shows evolution of the SPI and the SPEI over 3, 12, 24, and 48 month intervals from 1961 to 2006. Short timescales showed a high temporal frequency of dry and moist periods. With increasing timescales, drought and moist periods showed a lower temporal frequency and a longer duration. Two contrasting periods were evident between 1961 and 2006 for both the SPI and the 
occurred from 1980 to 2006, and were particularly severe during the period 1990-2005. Both indices showed a similar time evolution, with no notable differences. For example, at the 24-month timescale both indices demonstrated four major dry periods: from 1975 to 1976, in the first half of the 1980s, most of the 1990s, and from 2005 until the end of the analysis period. However, the average duration of droughts determined by the SPEI was longer than that identified by the SPI. This occurred at all analyzed timescales; at the timescale of 3 months the average duration of dry periods was 3.8 months according to the SPI, whereas the SPEI indicated an average duration of 4.1 months; at the scale of 12 months, the average durations were 10.7 and 13.0 months for the SPI and the SPEI, respectively; at the scale of 24 months the mean duration was 17.4 months for the SPI and 17.6 months for the SPEI. The longest average duration of dry periods (21.1 months) was registered by the SPEI at the 48-month scale, whereas the SPI showed a mean maximum duration of 19.6 months. The SPEI also identified a greater severity of droughts in the 1990s and 2000s than did the SPI; this was related to the very warm temperatures during those decades. Thus, the evolution of the drought indices is related to the observed changes of precipitation and temperature. The temperature shows a positive trend $\left(0.23{ }^{\circ} \mathrm{C}\right.$ per decade between 1961 and 2006) and precipitation a negative trend (-71 mm per decade between 1961 and 2006). Both trends are statistically significant (RhoSpearman test, $\mathrm{p}<0.05$ ). months). Correlations were positive for the various timescales, and the curves for the SPI and the SPEI were of similar shape. In general, climate variability explained a high proportion of variability in hydrological variables. Different responses were identified for inflow, reservoir storage, and outflow. The greatest correlations with inflow were found at timescales of 4-12 months, for both the 
the Entrepeñas and Buendía reservoirs (not shown). The maximum correlation was recorded for the SPEI at the 8-month timescale $(\mathrm{R}=0.76)$. It is notable that positive and high correlations were also found at long timescales. Reservoir storage and outflow showed a different behavior than did inflow. The greatest correlations were found for longer timescales and reservoir storage (a maximum of $\mathrm{R}=0.87$ with the 33-month SPEI), as a consequence of the hyperannual characteristics of the Entrepeñas-Buendía reservoir system. Thus, climatic conditions in the previous 3-4 years were the most significant variable accounting for water quantities stored in reservoirs. Correlations for outflow from the system were slightly lower, with an even longer temporal inertia (a maximum of $\mathrm{R}=0.76$ for the 48 -month SPEI).

This analysis showed that the reservoir system markedly changed the river regime, with inflow determined by relatively high frequencies of climate variability, and outflows by large scale frequencies, which were greatly influenced by dam operations. It is noteworthy that for both reservoir storage and outflow, correlation was slightly higher with the SPEI rather than the SPI, indicating that a combined effect of precipitation and evapotranspiration better explained variability of water resources than did precipitation alone.

Figure 7 shows the evolution of hydrological and climatic drought indices, with respect to each index and the timescale at which the highest correlation was found. For inflow there was a strong correlation between climatic and hydrological drought indices. Between 1960 and 1980 moist conditions dominated, explaining positive anomalies for inflows. In contrast, between 1980 and 2006 the climatic drought periods showed a significant reduction in inflow, with the exception of a few positive peaks (e.g., 1988, 1997, 1998), when there was agreement between positive climatic and hydrologic drought indices.

Reservoir storage also showed temporal variation closely related to evolution of the climatic drought index, with variability in climatic droughts explaining most anomalies in water resources in the reservoir system. Positive anomalies in reservoir storage were recorded during the moist period 
(1961-1980), whereas dominant negative anomalies in storage occurred after this time, coinciding

389 with negative SPEI values. Outflow from the system showed less relationship to the evolution of 390 climatic droughts. This was expected, as river management affects flows downstream of dams, but 391 in the study area after 1985 water transfer to Mediterranean basins also influenced outflow, which 392 caused a sudden drop in the influence of climatic control on releases to the Tagus River downstream 393 of the reservoir system.

394 As expected, the relationship between climatic and hydrological droughts changed markedly on a 395 monthly basis. Figure 8 shows Pearson's R correlations for the z-standardized inflow and the 1- to 48-month SPI and SPEI. The patterns for the SPI and SPEI were quite similar. Very high correlations ( $>0.9$ ) were found between hydrological and climatic droughts from January to March 398 for timescales between 3 and 5 months. In contrast, correlations during summer months were very 399 low at the shortest timescales, whereas inflow was more associated with drought indices at longer 400 timescales.

401 Figure 9 shows monthly correlations between z-standardized reservoir storage and the various 402 timescales for the SPI and the SPEI. As was expected from the hyperannual character of the 403 reservoir system, there were fewer monthly differences in this system than were found for inflow. 404 For most months the SPEI showed better correlations than did the SPI, and the strongest 405 correlations were found for timescales between 25 and 45 months. Outflow also showed stronger 406 correlations with the SPEI than with the SPI, few differences between months (Figure 10), and had 407 a similar pattern to that for reservoir storage.

409 4.3. Temporal changes in the hydrological response to climatic droughts

410 Figure 11 shows moving window correlations (15 years) for the SPI and the SPEI at various 411 timescales, and the z-standardized inflow. There were few changes during the analyzed period, 412 although after 1985 the correlations were slightly lower. Figures 12 and 13 compare SPI and SPEI 
data with reservoir storage and output, and reveal more important changes than were found for

414 inflow. For reservoir storage, correlations before 1975 were not significant at most timescales 415 considered. After 1975 the relationship between climatic and hydrologic conditions increased 416 noticeably, and, after 1990, the correlations were slightly stronger for the SPI than the SPEI. The 417 opposite was observed for outflow, where correlations were higher with the SPEI than the SPI. 418 Nevertheless, the period of significant correlations was very short (between 1975 and 1985), 419 showing that after the water transfer system was initiated the effect of climate variability in explaining release to the Tagus River practically disappeared.

421 Figure 14a shows river flow in the Tagus River basin upstream and downstream of the Zorita reservoir. Two highly contrasting flow periods are evident, in 1961-1980 and 1980-2006. As a consequence of reservoir management, the temporal variability of flow in the Tagus River between 1961 and 1980, recorded downstream of the Entrepeñas-Buendía system, was less than the natural variability (Figure 14b). However, some high flows $\left(>200 \mathrm{Hm}^{3}\right.$ ) were maintained and the frequency of low flows was reduced, relative to upstream reservoirs. After 1980 there was a dramatic change in the river regime. Between 1980 and 1995 high flows declined upstream of the Entrepeñas428 Buendía reservoirs, which could explain the reduction in high flows downstream of the reservoir 429 system. In the period 1995-2006 some high flows also occurred upstream of the reservoirs, but very 430 constant flows were recorded downstream. Thus, the total flow during the irrigation-free period 431 (November-May) was dramatically reduced in the 1995-2006 period (average $127.7 \mathrm{Hm}^{3}$ ) 432 compared with the 1985-1995 interval (average $188.1 \mathrm{Hm}^{3}$ ). Prior to initiation of the water transfer 433 system, the November-May flow had increased in the regarding 1985-1995 interval (average 500 $434 \mathrm{Hm}^{3}$ vs. $406.8 \mathrm{Hm}^{3}$, respectively). This indicates that greater inflow to the reservoirs increased the 435 flows released from the system, but there was a flow reduction to the Tagus River downstream of 436 the water transfer point, with increased flow being diverted to the water transfer system. This can be 437 explained by increased demand for water both in the Mediterranean basin and for irrigation in the 
438 Bolarque-Jarama area (Figure 14c). Thus, in the last 10 years the diversion of water to these uses

439 has exceeded the flow of the Tagus River downstream of the Zorita reservoir (annual average 647.5 $440 \mathrm{Hm}^{3}$ vs. $317 \mathrm{Hm}^{3}$, respectively).

\section{Discussion and conclusions}

This study evaluated the impact of climatic droughts on various hydrological systems in a highly regulated basin of central Spain between 1961 and 2006, using two different drought indices, the SPI and the SPEI. This is one of the first studies to explore the relationship between hydrological and climatic droughts using such indices.

We have shown that construction of hydrological drought indices based on a diversity of variables is complex because the statistical characteristics of series used can vary markedly. The procedure used to obtain indices differed for river discharge and reservoir storage because of differences in the statistical distributions most appropriate to the data, in this case the Pearson III distribution for river discharge and the Generalized Pareto distribution for reservoir storage. This highlights the need for prior testing to determine the most suitable distribution for deriving hydrological indices. This conclusion is in line with the recent results of Shukla and Wood (2008) in the United States of 456 America. The two climate drought indices (the SPI and the SPEI) effectively identified water deficits at various timescales. Independent of timescale and the drought index used, the results indicate that 459 drought conditions have increased in the headwaters of the Tagus River since the 1970s; the 460 decades of 1980, 1990, and 2000 were dominated by drought conditions. This finding is consistent 461 with most studies in the western Mediterranean (Van der Schrier et al., 2006; López-Moreno and 462 Vicente-Serrano, 2008) and the Iberian Peninsula (Esteban-Parra et al., 1998; Vicente-Serrano and 463 Cuadrat, 2007; De Luis et al., 2009), where a general decrease in precipitation occurred during the second half of the 20th century. Moreover, a marked increase in temperature was also seen in the 
region during this period (Brunet et al., 2006). These conditions have impacted on water resources, increasing evapotranspiration rates, the water deficit, and climate drought severity (e.g., Hu and Willson, 2000; Dubrovsky et al., 2008).

The recent increase in temperature could explain why climatic droughts in the decades of 1990 and 2000 were more severe when analyzed by the SPEI rather than the SPI. We also showed that the response to the hydrological drought was slightly higher according to SPEI data than SPI information, which indicates that although precipitation plays a major role in explaining temporal variability in analyzed variables, the influence of temperature is significant and is likely to increase in the future, as has been indicated in numerous studies (Labat et al., 2004; Nichols, 2004; Buthiyani et al., 2008; Polemio and Casarano, 2008).

We showed that the response of river discharge in the headwaters of the Tagus River was similar when measured by either drought index. This was because of the greater sensitivity of river discharge to climate variability at short timescales, and highlights the difficulty of isolating of temperature variability and trends from variation in unregulated river discharge. In contrast, a greater difference was found between the SPI and the SPEI when reservoir storage was examined; this responds over longer timescales, and the cumulative role of temperature was evident in the drought indices. In addition, various studies have shown that reservoirs are subject to evaporation processes (Maingi and Marsh, 2002; Montasery and Adeloye, 2004). These factors could explain why a combined precipitation and evapotranspiration drought index, such as the SPEI, is more appropriate for analysis of the response of reservoir storage than an index, such as the SPI, that considers precipitation alone. Moreover, water demand for crops is highly dependent on temperature, and warmer conditions may enhance water consumption in the Mediterranean and irrigation areas of the basin. As outflow is highly dependent on storage in the reservoir system, the role of Potential Evapotranpiration is also propagated downstream, and, thus, stronger correlations are found with the SPEI than the SPI. 
It is noteworthy that the greatest responses to hydrological variables seen in the climatic drought 491 indices were noted over longer timescales in the headwaters of the Tagus basin than in other regions. Vicente-Serrano and López-Moreno (2005) showed that in the central Spanish Pyrenees the greatest responses were in the 2-month SPI for river discharge and the 8-month SPI for reservoir storage. In Hungary, Szalai et al. (2000) also found greater responses for river discharge and reservoir storage over shorter timescales than we found in the Tagus basin. The response of river 496 discharge to long timescales (24-48 months) may be attributable to the dominant limestone 497 lithology. This may favor an indirect relationship between precipitation and discharge, with recharge of aquifers during precipitation periods, but release occurring slowly over long intervals. The drought indices for the analyzed reservoir storage were not affected by short timescales, but a strong response over longer timescales (3-4 years) was found. This is explained by the relatively 501 large inertia of inflow, in addition to the hyperannual character of the managed system. There were no marked monthly differences in responses of drought indices to different timescales for reservoir storage and outflow, because of the low response found at the shortest timescales. Nevertheless, the indices showed large monthly differences in response to inflow to the system, which were closely related to the climatic-lithological characteristics of the region. Precipitation in 506 the headwaters of the Tagus River is heavily influenced by southwestern flows associated with 507 negative phases of the North Atlantic Oscillation (López-Moreno et al., 2007), which is a major influence in winter. This explains the strong correlation found between river discharge and the 2- to 509 5-month SPI and SPEI between December and March, as surface flow is dominant in these months. 510 Further, the main recharge of aquifers occurs during winter, which explains the annual or bi-annual 511 recharge seen and the greater influence of variability in summer flow on the SPI and the SPEI at the 512 longest timescales. The baseline aquifer levels are affected mainly in summer, and show slow 513 temporal inertia and a strong relationship to precipitation accumulated over long periods (Peters et 514 al., 1995); the drought index responses are also over longer timescales (Khan et al., 2008). 
515 The relationship between climate and hydrological conditions was relatively stable between 1961 516 and 2006 with respect to unregulated inflow to the system (upstream of the Entrepeñas-Buendía 517 reservoirs), but slight decreases in correlation were found after the 1980s. Given the absence of 518 human interference upstream of the reservoir, this decrease was probably attributable to land cover 519 changes dominated by an increase in natural vegetation cover. In the mountainous areas of central 520 Iberian Peninsula several studies have illustrated the existing re-vegetation process as the dominant 521 land cover change (e.g., Gallart and Llorens, 2002). For example, Hill et al. (2008) showed, by 522 means of NOAA-AVHRR images, that in the headwaters of the Tagus basin the dominant land 523 cover process is a trend toward the natural vegetation recovering as a consequence of the rural 524 exodus.The increased evapotranspiration demand and water interception by vegetation, and reduced 525 the effect of climate in explaining flow variability, as has been observed in other areas of the Iberian 526 Peninsula (Beguería et al., 2003; García-Ruiz et al., 2008).

527 Nevertheless, the main changes in climatic-hydrological relationships occurred in the regulated systems of reservoir storage and outflow. These were closely related to changes in external demand 529 with commencement of the water transfer system to the Júcar and Segura basins after the 1980s. 530 Although reservoir storage was closely related to low-frequency climate variability in recent 531 decades, the outflow to the Tagus River downstream of the reservoir system was not controlled by 532 climate after the water transfer system commenced. This situation leads to enormous uncertainty as to the future availability of water resources. On the one hand, demand for water from the transfer system has increased markedly in recent years, dramatically reducing water release to the Tagus 535 River. On the other hand, the increased frequency and severity of climatic droughts in the last 536 decades has reduced water reserves stored in the reservoirs. Despite the marked reduction of water 537 availability in the basin, there has been no reduction in the amount of water transferred; rather, there 538 has been a clear trend of increasing water demand in the Mediterranean basin. Therefore, despite 539 the onset of a period characterized by reduced availability of water resources because of more 
frequent and severe droughts, water managers have given priority to water transfer for human use

541 over maintenance of natural flow to the Tagus River, which has dramatically declined. This management practice has relied on the hyperannual character of the Entrepeñas-Buendía reservoir system, which reduces the effect of short-term drought. However, under the severe and sustained droughts recorded since the 1990s the reservoir system has not been able to maintain this management strategy. This was evident in 2005 and 2006, when sustained drought conditions resulted in the reservoir being unable to satisfy demand, and the managers were obligated to reduce flow to both the Tagus River and the water transfer system for the Mediterranean basin; this resulted in conflicts and political ramifications at the national level. Given the context of global climate change, characterized by predictions of greater severity and frequency of droughts in southern Europe (Blenkinsop and Fowler, 2007), and continuing revegetation processes, water availability in the basin is expected to decline. Thus, it will be increasingly difficult or impossible to satisfy external water demand using the current management strategy, and it is likely that new approaches will be needed.

\section{Acknowledgements}

This work has been supported by the research projects CGL2006-11619/HID, CGL200801189/BTE, and CGL2008-1083/CLI financed by the Spanish Commission of Science and Technology and FEDER, EUROGEOSS (FP7-ENV-2008-1-226487) and ACQWA (FP7-ENV2007-1- 212250) financed by the VII Framework Programme of the European Commission, STRIVER (Strategy and methodology for Improved IWRM-An integrated interdisciplinary assessment in four twinning river basins), financed by the VI Framework Programme of the European Commision. "Las sequías climáticas en la cuenca del Ebro y su respuesta hidrológica" Financed by "Obra Social La Caixa” and the Aragón Government and "Programa de grupos de investigación consolidados” financed by the Aragón Government.

\section{Referentes}

Abramopoulos, F., Rosenzweig, C. and Choudhury B., (1988): Improved ground hydrology calculations for global climate models (GCMs): Soil water movement and evapotranspiration. Journal of Climate 1: 921-941.

Abramowitz, M., Stegun, I.A., (1965): Handbook of Mathematical Functions. Dover Publications, New York.

Alexandersson, H. (1986): A homogeneity test applied to precipitation data. Journal of Climatology 6: 661-675. 
Alexanderson, H., and Moberg, A. (1997): Homogeneization of swedish temperatura data. Part 1: homogenety test for linear trends. International Journal of Climatology 17: 25-34.

Batalla R.J., Kondolf G.M., Gómez C.M., (2004): Hydrological alterations in the Ebro Basin caused by dams. Journal of Hydrology 290, 117-136.

Begert, M., Schlegel, T. (2005): Homogeneous temperature and precipitation series of Switzerland from 1894 to 2000. International Journal of Climatology 25: 65-80.

Beaulieu, C., Ouarda, T, and Seidou, O. (2007): A review of homogenization techniques for climate data and their applicability to precipitation series. Hydrological Sciences Journal-Journal des Sciences Hydrologiques 52: 18-37.

Beguería, S., López-Moreno, J.I., Lorente, A., Seeger, M., García-Ruiz, J.M., 2003. Assessing the effects of climate oscillations and land-use changes on streamflow in the Central Spanish Pyrenees. Ambio 32, 283-286.

Bhutiyani, M.R., Kale, V.S., Pawar, N.J. (2008): Changing streamflow patterns in the rivers of northwestern Himalaya: Implications of global warming in the 20th century. Current Science 95: 618-626

Blenkinsop, S., and Fowler H.J. (2007). Changes in European drought characteristics projected by the PRUDENCE regional climate models, International Journal of Climatology, 27, 15951610 .

Brunet, M., Saladié, O., Jones, P., Sigró, J., et al., (2006) The development of a new dataset of Spanish daily adjusted temperature series (SDATS) (1850-2003). International Journal of Climatology 26: 1777-1802.

Cai, W., Cowan, T., (2008): Evidence of impacts from rising temperature on inflows to the Murraydarling basin. Geophysical Research Letters 35, L07701, doi: 10.1029/2008GL033390.

Chang, T.J., Cleopa, X.A., (1991): A proposed method for drought monitoring. Water Resources Bulletin, 27: 275-281.

Changnon, S. A., Easterling,W. E., (1989): Measuring drought impacts: the Illinois case, Water Resources Bulletin, 25, 27-42.

De Luis, M., González-Hidalgo, J.C., Longares, L.A., Stepanek, P., (2009): Seasonal precipitation trends in the Mediterranean Iberian Peninsula in second half of 20th century. International Journal of Climatology, in press.

Dracup, J. A., Lee, K., Paulson, E.G., (1980): On the definition of droughts, Water Resour. Res., 16, 297-302.

Dubrovsky, M., Svoboda, M.D., Trnka, M., Hayes, M.J., Wilhite, D.A., Zalud, Z. and Hlavinka, P., (2008): Application of relative drought indices in assessing climate-change impacts on drought conditions in Czechia. Theoretical and Applied Climatology, in press.

Elfatih, A., Eltahir, B., Yeh, P. J. F., (1999): On the asymmetric response of aquifer water level to floods and droughts in Illinois, Water Resour. Res., 35, 1199-1217.

Esteban-Parra, M.J., Rodrigo, F.S., Castro-Diez, Y. (1998): Spatial and temporal patterns of precipitation in Spain for the period 1880-1992. International Journal of Climatology, 18: 1557-1574.

Fleig, A. K., Tallaksen, M., Hisdal, H., Demuth, S., (2006): A global evaluation of streamflow drought characteristics, Hydrol. Earth Syst. Sci., 10, 532- 552.

Gallart, F. and Llorens, P., (2002): Water resources and environmental change in Spain. A key issue for sustainable integrated catchment management. In Environmental Change and Water Sustainability. (J.M. García-Ruiz, J.A.A. Jones \& J. Arnáez Eds.). Zaragoza: 11-20.

García-Ruiz, J.M., Regüés, D., Alvera, B., Lana-Renault, N., Serrano-Muela, P., Nadal-Romero, E., Navas, A., Latron, J., Martí-Bono, C., Arnáez, J., (2008): Flood generation and sediment transport in experimental catchments affected by land use changes in the central Pyrenees. Journal of Hydrology 356, 245-260. 
García-Ruiz, J.M., López-Moreno, J.I., Vicente-Serrano, S.M., Lasanta, T., Beguería, S., (2009): Mediterranean water resources in a global change scenario. Earth Science Reviews. Under review.

Garrote L, A. Iglesias, M. Moneo, A. Garrido, A. Gómez, A. Lapeña, S. Benbeniste, F. Cubillo, J.C. Ibáñez (2007), Application of the drought management guidelines in Spain. Options Méditerranéennes, B, 58, 373-406

Gerten, D., Rost, S., von Bloh, W., Lucht, W., (2008): Causes of change in 20th century global river discharge. Geophysical Research Letters 35: art. no. L20405

Giorgi, F., Lionello, P., (2008): Climate change projections for the Mediterranean region. Global and Planetary Change 63, 90-104.

Greenwood, J. A., Landwehr, J. M., Matalas, N. C., Wallis, J.R., (1979): Probability weighted moments: Definition and relation to parameters of several distributions expressible in inverse form, Water Resour. Res., 15, 1049- 1054.

Heim, R.R., (2002): A review of twentieth-century drought indices used in the United States. Bulletin of the American Meteorological Society. 83: 1149-1165.

Hill, J., Stellmes, M., Udelhoven, T., Röder, A. and Sommer, S., (2008): Mediterranean desertification and land degradation: Mapping related land use change syndromes based on satellite observations. Global and Planetary Change 64: 146-157

Hosking, J. R. M. (1990): L-Moments: Analysis and estimation of distributions using linear combinations of order statistics, J. R. Stat. Soc. B, 52, 105- 124.

Hu, Q., Willson, G.D., (2000): Effect of temperature anomalies on the Palmer drought severity index in the central United States. International Journal of Climatology. 20: 1899-1911.

Jones, P.D., Hulme, M., (1996): Calculating regional climatic time series for temperature and precipitation: methods and illustrations. International Journal of Climatology 16: 361-377.

Jones, P.D., Moberg, A., (2003): Hemispheric and large-scale surface air temperature variations: An extensive revision and an update to 2001. Journal of Climate 16: 206-223.

Khan, S., Gabriel, H.F. Rana, T. (2008): Standard precipitation index to track drought and assess impact of rainfall on watertables in irrigation areas. Irrigation and Drainage Systems 22: 159-177.

Kilsby, C.G., Tellier, S.S., Fowler, H.J., Howels, T.K. (2007): Hydrological impacts of climate change on the Tejo and Guadiana Rivers. Hydrology and Earth System Sciences 11, 11751189.

Labat, D., Goddéris, Y., Probst, J.L., Guyot, J.L. (2004) Evidence for global runoff increase related to climate warming. Advances in Water Resources 27: 631-642.

Lasanta, T., Vicente Serrano, S.M., Cuadrat, J.M., (2005): Spatial-temporal variability of the plant landscape in the mediterranean highlands due to the abandonment of traditional land uses: a study of the Spanish Central Pyrenees. Applied Geography 25: 47-65.

Llorens, P., Poch, R., Rabada, D., Gallart, F., (1995): Study of the changes of hydrological processes induced by afforestation in Mediterranean mountainous abandoned fields. Physics \& Chemistry of the Earth 20, 375-383.

Lopez-Bustins, J.-A., Martin-Vide, J., Sanchez-Lorenzo, A., (2008): Iberia winter rainfall trends based upon changes in teleconnection and circulation patterns. Global and Planetary Change 63, 171-176.

López-Moreno, J.I., Beguería, S., Vicente-Serrano, S.M. y García-Ruiz, J.M. (2007) The Influence of the NAO On Water Resources In Central Iberia: Precipitation, Streamflow Anomalies And Reservoir Management Strategies. Water Resources Research. W09411 doi: 10.1029/2007WR005864.

López-Moreno, J.I., Vicente-Serrano, S.M., (2008) Extreme phases of the wintertime North Atlantic Oscillation and drought occurrence over Europe: a multi-temporal-scale approach. Journal of Climate 21, 1220-1243. 
López-Moreno, J.I., Vicente-Serrano, S.M., Beguería, S. García-Ruiz, J.M., Portela, M. M., Almeida, A.B., (2009): Downstream propagation of hydrological droughts in highly regulated transboundary rivers: the case of the Tagus River between Spain and Portugal. Water Resources Research 45, W02405, doi:10.1029/2008WR007198.

MacDonald, D., Crabtree, J.R., Wiesinger, G., Dax, T., Stamou, N., Fleury, P., Lazpita, J.G., Gibon, A., (2000): Agricultural abandonment in mountain areas of Europe: Environmental consequences and policy response. Journal of Environmental Management 59, 47-69.

Maingi J.K., Marsh s.e. (2002). Quantifying hydrologic impacts following dam construction along the Tana River, Kenia. Journal of Arid Environments, 50: 53-79.

Maneux E., Probst J.L., Veyssy E. y Etcheber H. 2001. Assessment of dam trapping efficiency from water residence time: Application to fluvial sediment transport in the Adour, Dordogne, and Garonne River basins. K (2001). Water Resources Research, 37 (3), 801-811.

McKee, T.B.N., Doesken, J., Kleist, J., (1993): The relationship of drought frecuency and duration to time scales. Eight Conf. On Applied Climatology. Anaheim, CA, Amer. Meteor. Soc. 179-184.

McKee, T. B. N., Doesken, J., Kleist, J., (1995): Drought monitoring with multiple time scales, Ninth. Conf. On Applied Climatology, Dallas, TX, Amer. Meteor. Soc., 233-236.

Montaseri M., Y Adeloye A.J. (2004). A graphical rule for volumetric evaporation loss correction in reservoir capacity-yiel-performanc planning in Urmia region, Irán. Water Resources Management, 18: 55-74.

Nicholls, N., (2004): The changing nature of Australian droughts. Climatic Change 63: 323-326.

Pandey, R.P., Ramasastri, K.S., (2001): Relationship between the common climatic parameters and average drought frequency, Hydrological Processes, 15: 1019-1032.

Patel, N.R., Chopra, P., and Dadhwal, V.K. (2007): Analyzing spatial patterns of meteorological drought using standardized precipitation index. Meteorological Applications, 14: 329-336.

Peters, E., van Lanen, H. A. J., Torfs, P. J. J. F., Bier, G., (2005): Drought in groundwater-drought distribution and performance indicators, J. Hydrology 306: 302-317.

Peterson, T., Easterling, R., (1994): Creation of homogeneous composite climatological reference series. International Journal of Climatology 14: 671-679.

Peterson, T.C., Easterling, D.R., Karl, T.R., et al., (1998): Homogeneity adjustments of in situ atmospheric climate data: a review. International Journal of Climatology. 18: 1493-1517.

Polemio, M., Casarano, D. 2008 Climate change, drought and groundwater availability in southern Italy Geological Society Special Publication 288: 39-51

Räisänen, J. (2007): How reliable are climate models?. Tellus, Series A: Dynamic Meteorology and Oceanography 59: 2-29.

Sims, A.P., Nigoyi, D.S. and Raman, S., (2002): Adopting indices for estimating soil moisture: A North Carolina case study. Geophysical Research Letters 29: 1-4.

Skøien, J. O., Blösch, G., Western, A. W., (2003): Characteristic space scales and timescales in hydrology, Water Resour. Res., 39, 1304, doi:10.1029/2002WR001736, 2003.

Shukla, S., Wood, A.W., (2008): Use of a standardized runoff index for characterising hydrologic drought. Geophysical Research letters, 35, L02405, doi: 10.1029/2007GL032487.

Siegel, S., Castelan, N. J. (1988): Nonparametric Statistics for the Behavioral Sciences, McGrawHill, New York.

Sluiter, R., De Jong, M., (2007): Spatial patterns of Mediterranean land abandonment and related land cover transition. Landscape Ecology 22, 559-576.

Snoussi M., Haïda S. y Imassi S. 2002. Effects of the construction of dams on the water and sediment fluxes of the Moulouya and the Sebou rivers. Morocco. Regional Environmental Change 3, 5-12.

Stepánek P. 2004. AnClim - Software for Time Series Analysis (for Windows). Department of Geography, Faculty of Natural Sciences, Masaryk University: Brno, 1.47 MB. 
Syed, T. H., Famiglietti, J.S., Rodell, M., Chen, J. and Wilson, C.R., (2008): Analysis of terrestrial water storage changes from GRACE and GLDAS, Water Resources Research 44, W02433, doi:10.1029/2006WR005779.

Szalai, S., Szinell, C. S., Zoboki, J. (2000): Drought monitoring in Hungary, in: Early warning systems for drought preparedness and drought management, World Meteorological Organization, Lisbon, 182-199, 2000.

Tallaksen, L.M., Madsen, H., Clausen, B., (1997): On the definition and modelling of streamflow drought duration and deficit volume, Hydrol. Sci. J., 42, 15- 33.

Vasiliades, L., Loukas, A., (2009): Hydrological response to meteorological drought using the Palmer drought indices in Thessaly, Greece. Desalination 237: 3-21.

Van der Schrier, G., K. R. Briffa, P. D. Jones, and T. J. Osborn, 2006: Summer moisture variability across Europe. J. Climate, 19, 2818-2834.

Vicente Serrano, S.M., Lasanta, T., Romo, A., (2004): Analysis of the spatial and temporal evolution of vegetation cover in the Spanish central Pyrenees: the role of human management. Environmental Management 34: 802-818.

Vicente Serrano, S.M., López-Moreno, J.I., (2005): Hydrological response to different time scales of climatological drought: an evaluation of the standardized precipitation index in a mountainous Mediterranean basin. Hydrology and Earth System Sciences 9: 523-533.

Vicente-Serrano, S.M., (2006), Differences in spatial patterns of drought on different time scales: an analysis of the Iberian Peninsula. Water Resources Management 20: 37-60.

Vicente-Serrano, S.M., Cuadrat-Prats, J.M., (2007): Trends in drought intensity and variability in the middle Ebro valley (NE Spain) during the second half of the twentieth century. Theoretical and Applied Climatology, 88: 247-258.

Vicente-Serrano S.M., Santiago Beguería, Juan I. López-Moreno, (2009): A Multi-scalar drought index sensitive to global warming: The Standardized Precipitation Evapotranspiration Index - SPEI. Journal of Climate. Under review.

Zaidman, M.D., Rees, H.G., Young, A.R., (2001): Spatio-temporal development of streamflow droughts in north-west Europe, Hydrol. Earth Syst. Sci., 5, 733-751. 
Figure 1. Location and topography of the study area, and the spatial distribution of weather and gauging stations used in analysis.

Figure 2. L-moment ratio diagram, including monthly series of river discharges, inflows to the Entrepeñas-Buendía system, reservoir storage, and outflow to the Tagus basin.

Figure 3. Evolution of hydrological drought indices for inflow, reservoir storage, and outflow to the system.

Figure 4. Flow chart that shows all steps of the methodology applied.

Figure 5. Evolution of the 3-, 12-, 24-, and 48-month SPI and SPEI in the study area from 1961 to 2006.

Figure 6. Pearson R correlation values for the 1- to 48-month SPI and SPEI, and series of zstandardized inflows, storages, and outflows.

Figure 7. Evolution of hydrological and climatic drought indices. The most highly correlated timescale is shown for each hydrological variable.

Figure 8. Correlation coefficients between the z-standardized monthly inflow series and the monthly SPI and SPEI values at various timescales. Significant correlations $(p<0.05)$ correspond to $\mathrm{R}$ values greater than 0.26 .

Figure 9. Correlation coefficients between the z-standardized monthly reservoir storage series and the monthly SPI and SPEI values at various timescales. Significant correlations $(p<0.05)$ correspond to $\mathrm{R}$ values greater than 0.26 .

Figure 10. Correlation coefficients between the z-standardized monthly outflow series and the monthly SPI and SPEI values at various timescales. Significant correlations $(p<0.05)$ correspond to $\mathrm{R}$ values greater than 0.26 .

Figure 11. Moving-window Pearson R correlation coefficients between the z-standardized monthly outflow series and the monthly SPI and SPEI values at various timescales. Significant correlations $(p<0.05)$ correspond to $\mathrm{R}$ values greater than 0.51 .

Figure 12. Moving-window R-Pearson correlation coefficients between the z-standardized monthly reservoir storage series and the monthly SPI and SPEI values at various timescales. Significant correlations $(p<0.05)$ correspond to $\mathrm{R}$ values greater than 0.51 .

Figure 13. Moving-window R-Pearson correlation coefficients between the z-standardized monthly outflow series and the monthly SPI and SPEI values at various timescales. Significant correlations $(p<0.05)$ correspond to $\mathrm{R}$ values greater than 0.51 .

Figure 14. a) Flows in the Tagus River upstream and downstream of the intake point for the water transfer system, b) inflows to the Entrepeñas-Buendía system, and, c) monthly flows for water transfer and irrigation. 


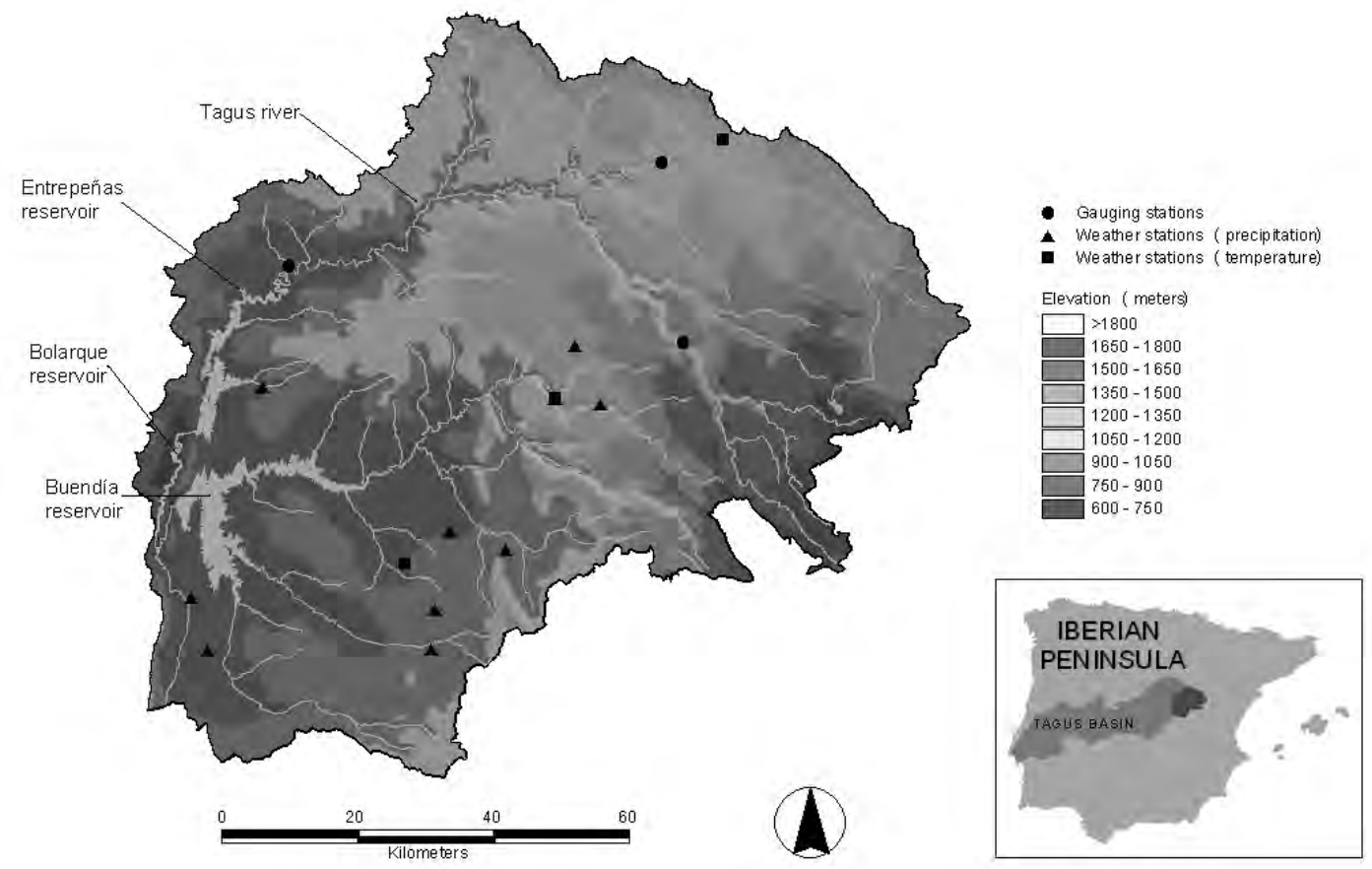

794 Figure 1. Location and topography of the study area, and the spatial distribution of weather and 795 gauging stations used in analysis. 


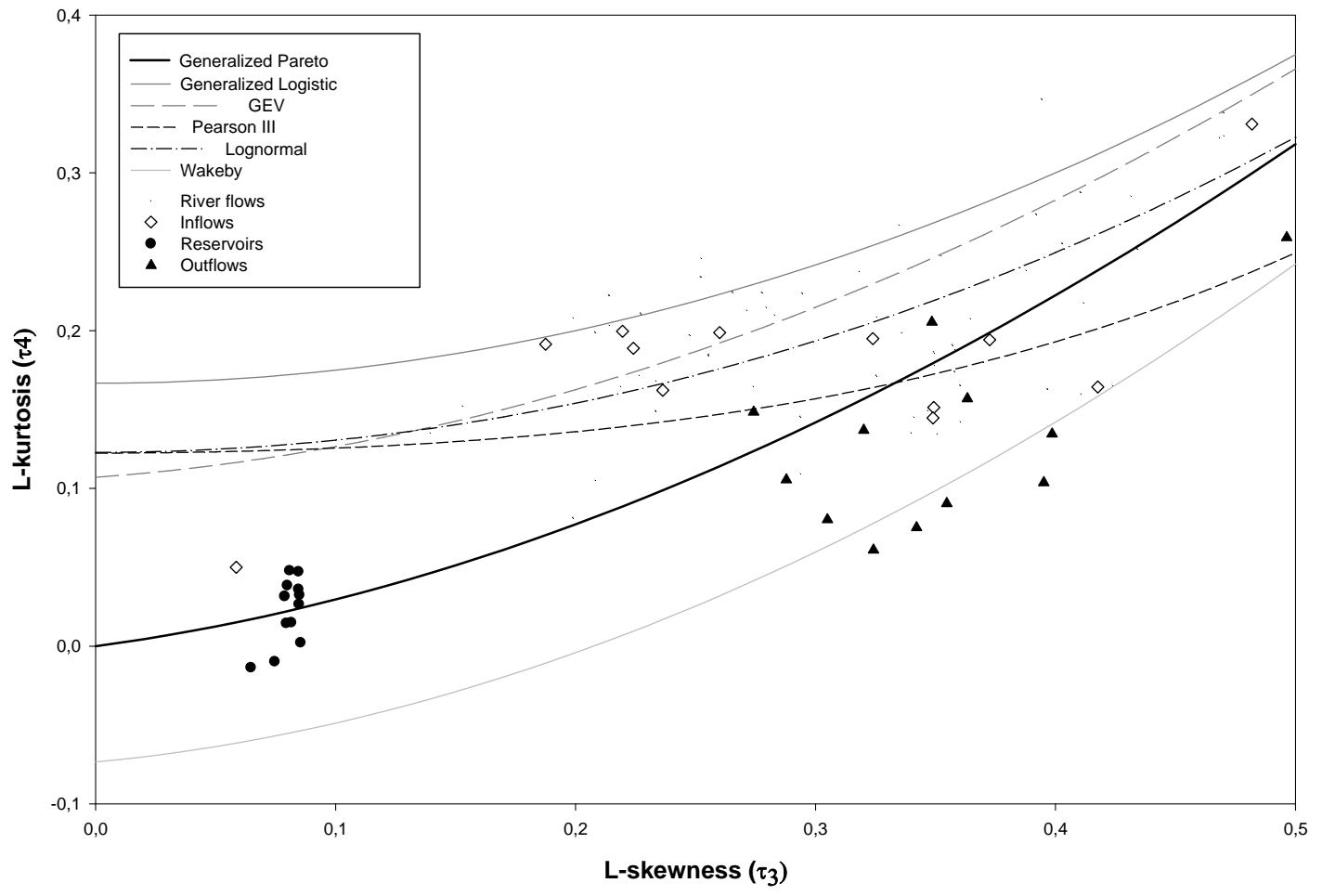

796

797

798

Figure 2. L-moment ratio diagram, including monthly series of river discharges, inflows to the Entrepeñas-Buendía system, reservoir storage, and outflow to the Tagus basin. 

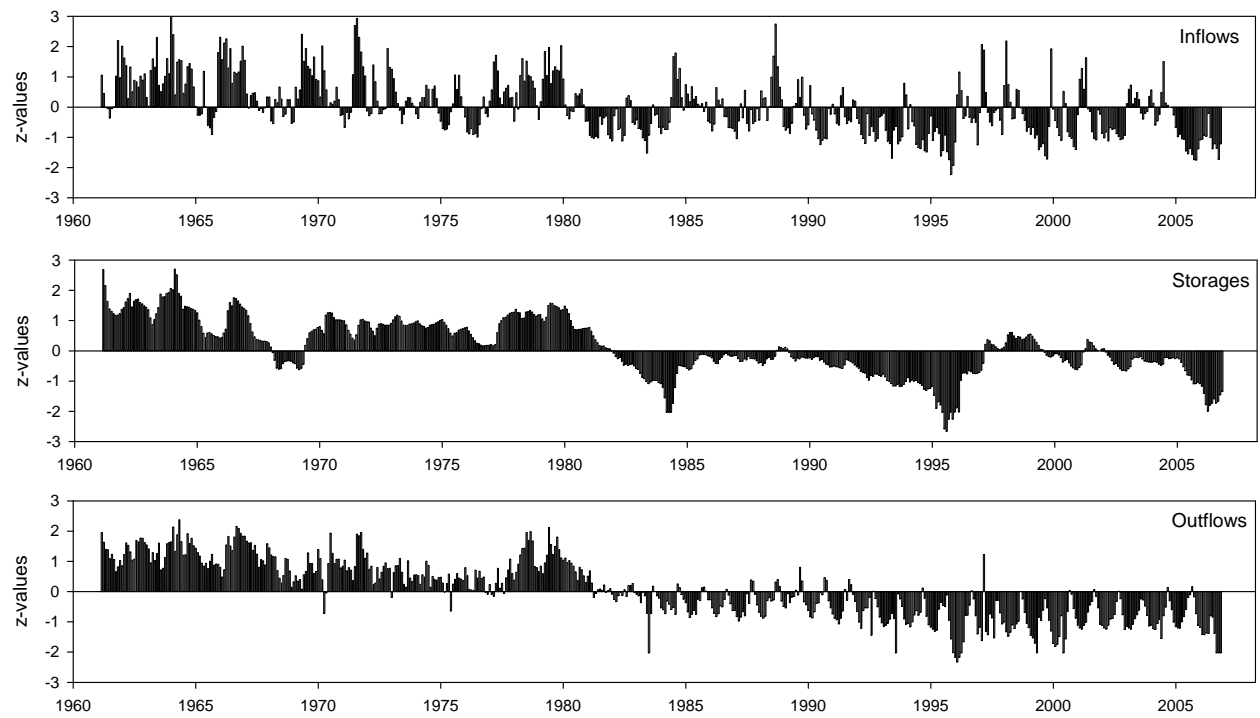

801

Figure 3. Evolution of hydrological drought indices for inflow, reservoir storage, and outflow to the system. 


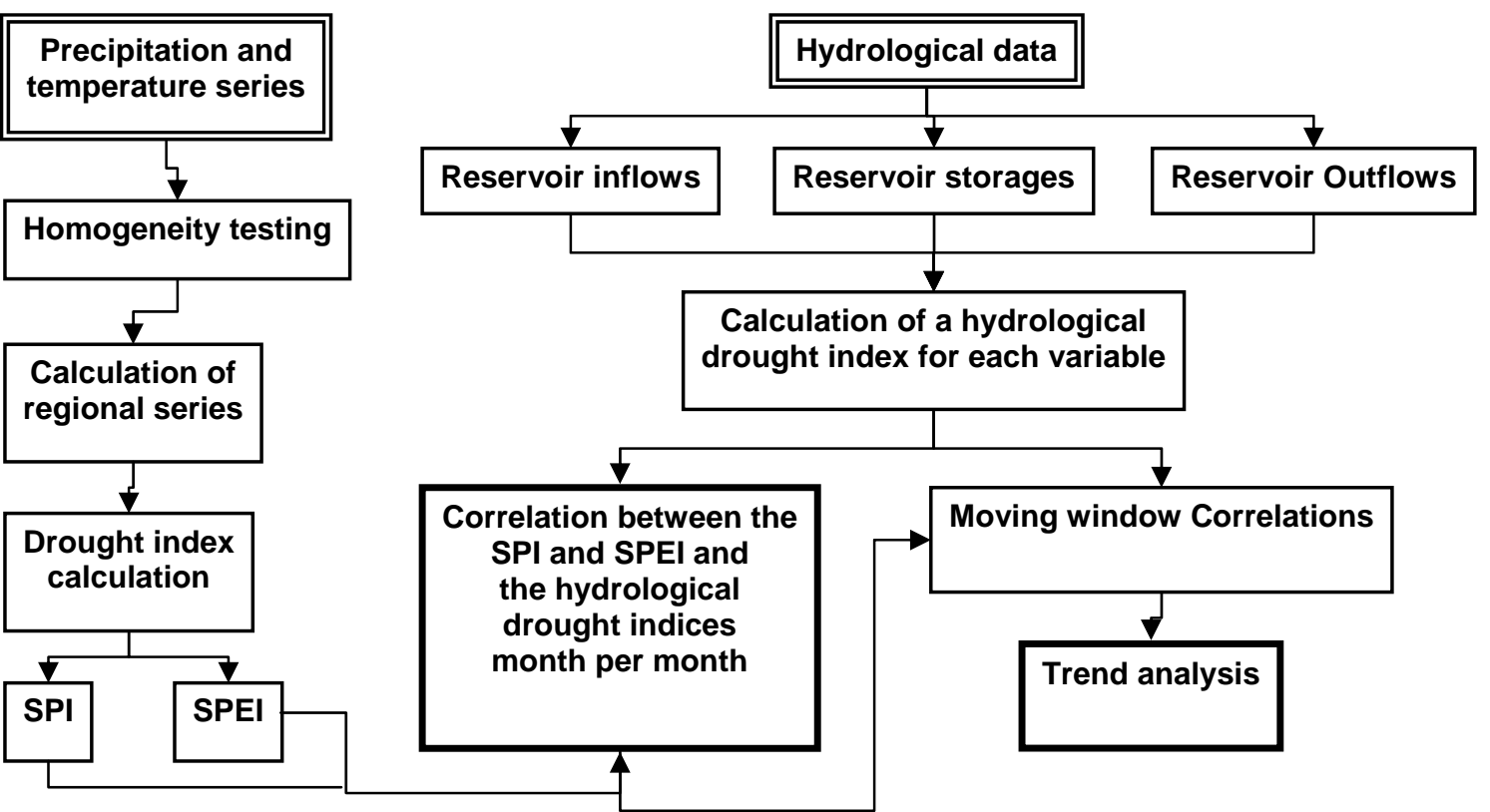

Figure 4. Flow chart that shows all steps of the methodology applied. 

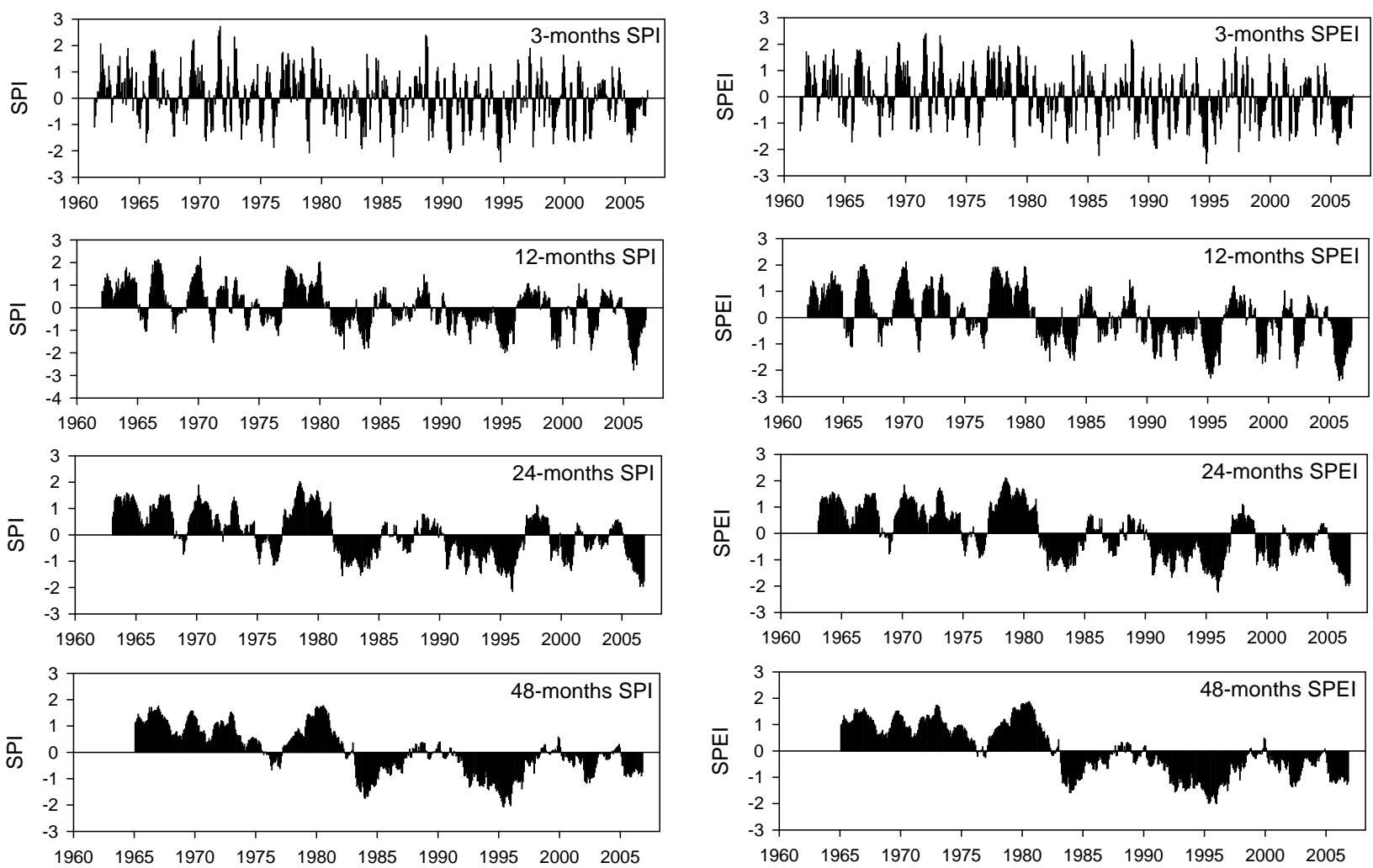

Figure 5. Evolution of the 3-, 12-, 24-, and 48-month SPI and SPEI in the study area from 1961 to 2006. 

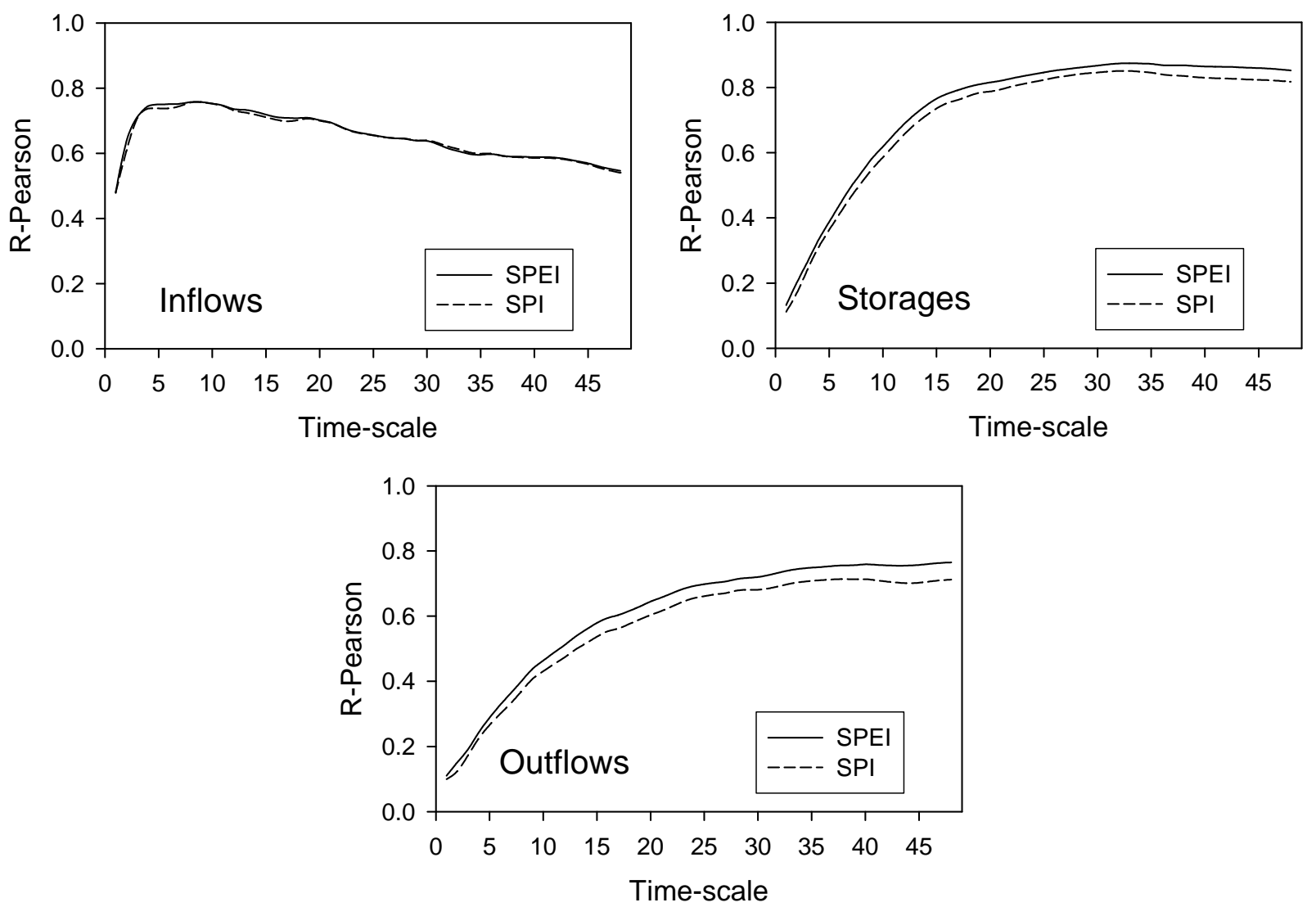

811 Figure 6. Pearson R correlation values for the 1- to 48-month SPI and SPEI, and series of z812 standardized inflows, storages, and outflows. 

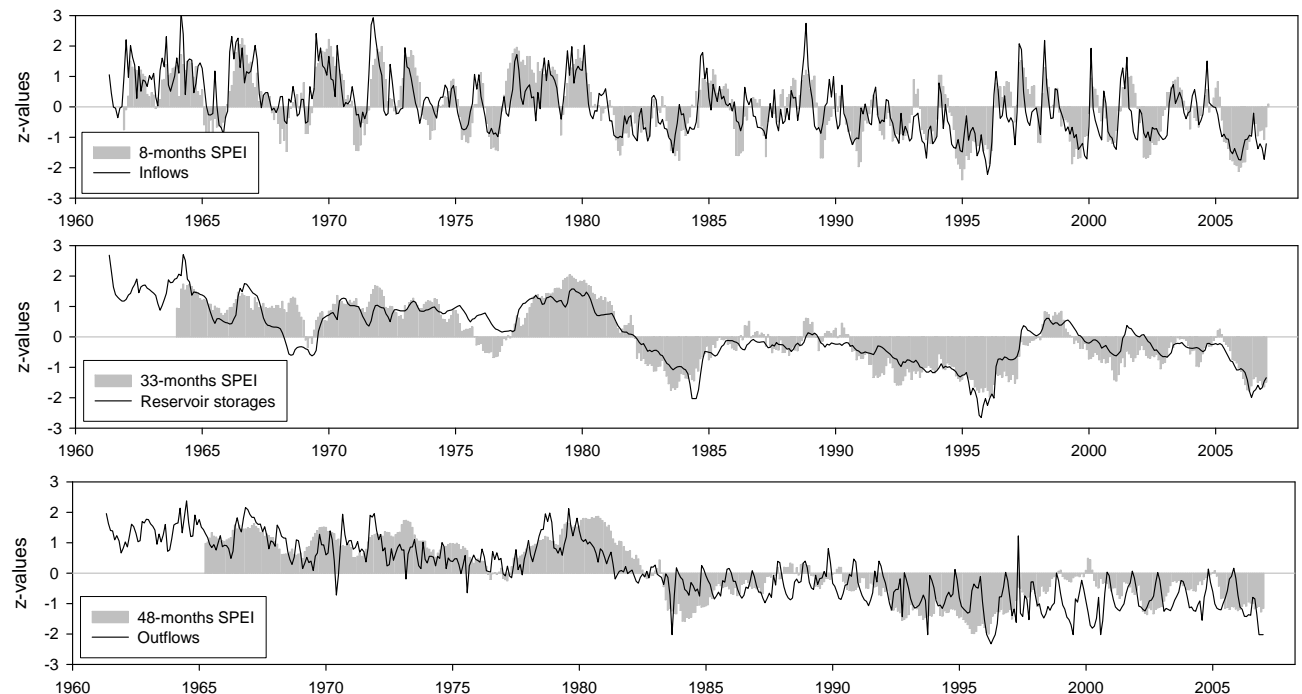

813

814

815

816
Figure 7. Evolution of hydrological and climatic drought indices. The most highly correlated timescale is shown for each hydrological variable. 

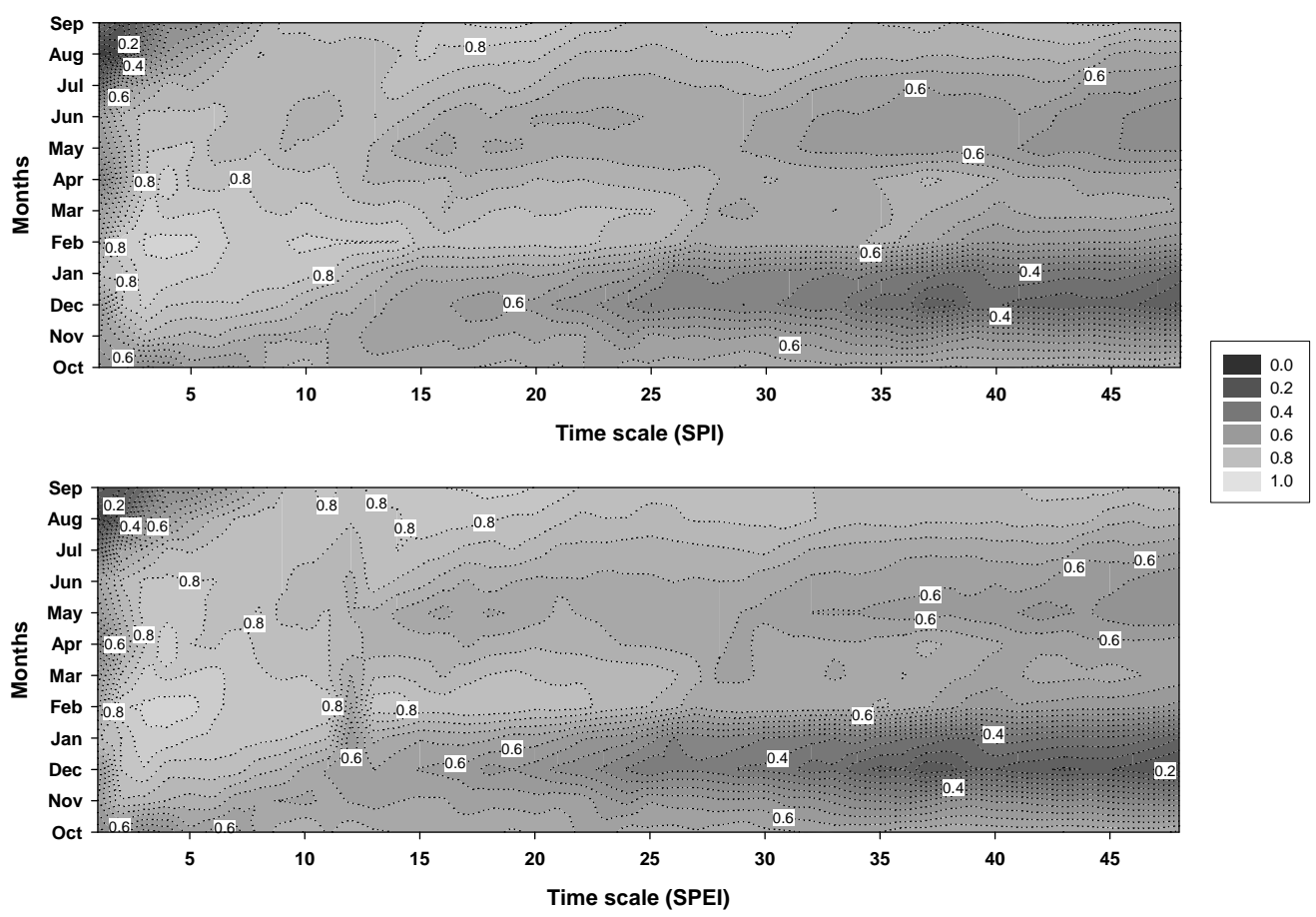

Figure 8. Correlation coefficients between the z-standardized monthly inflow series and the monthly SPI and SPEI values at various timescales. Significant correlations $(p<0.05)$ correspond to $\mathrm{R}$ values greater than 0.26 . 

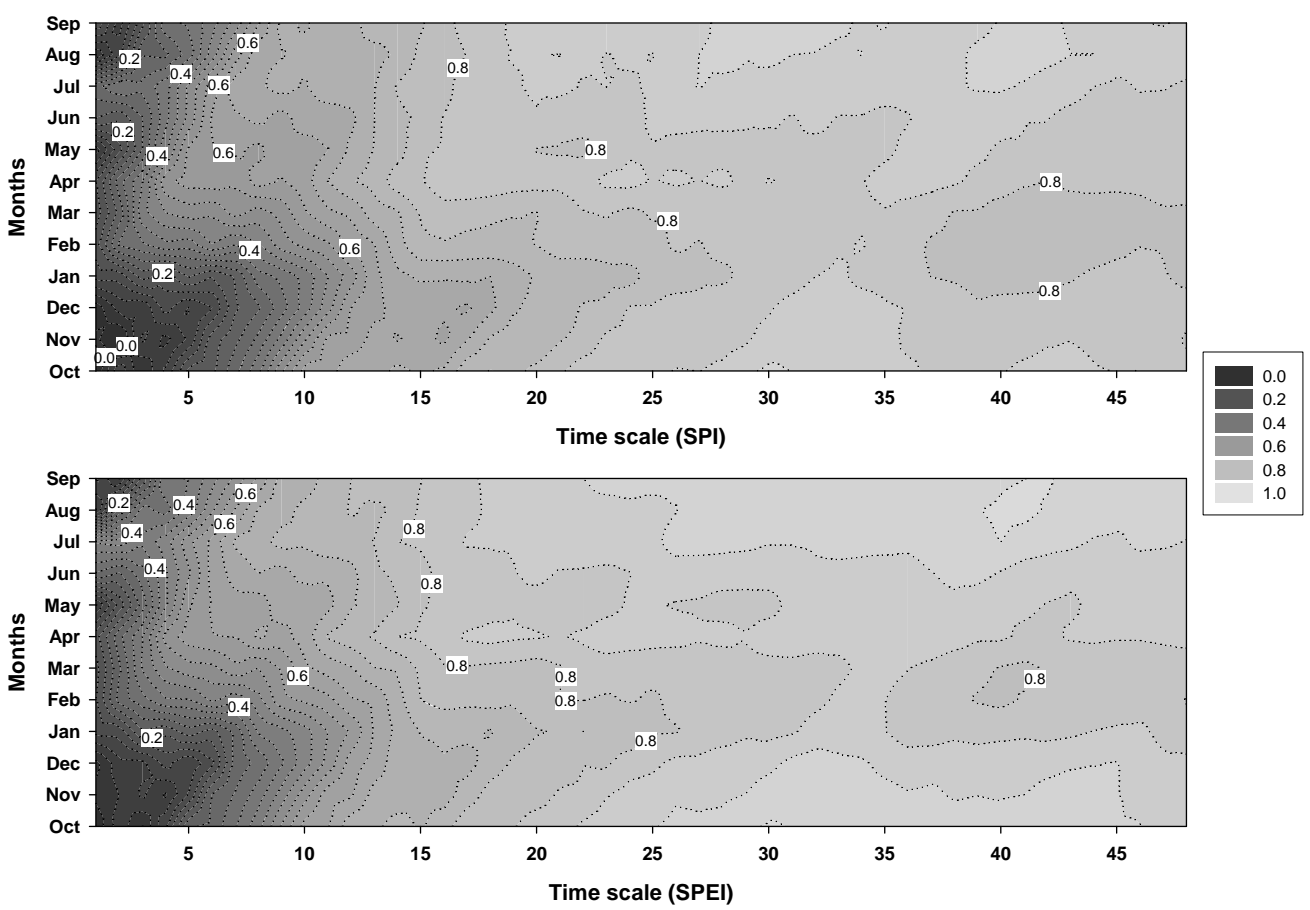

824 Figure 9. Correlation coefficients between the z-standardized monthly reservoir storage series and 825 the monthly SPI and SPEI values at various timescales. Significant correlations $(p<0.05)$ correspond to $\mathrm{R}$ values greater than 0.26 . 

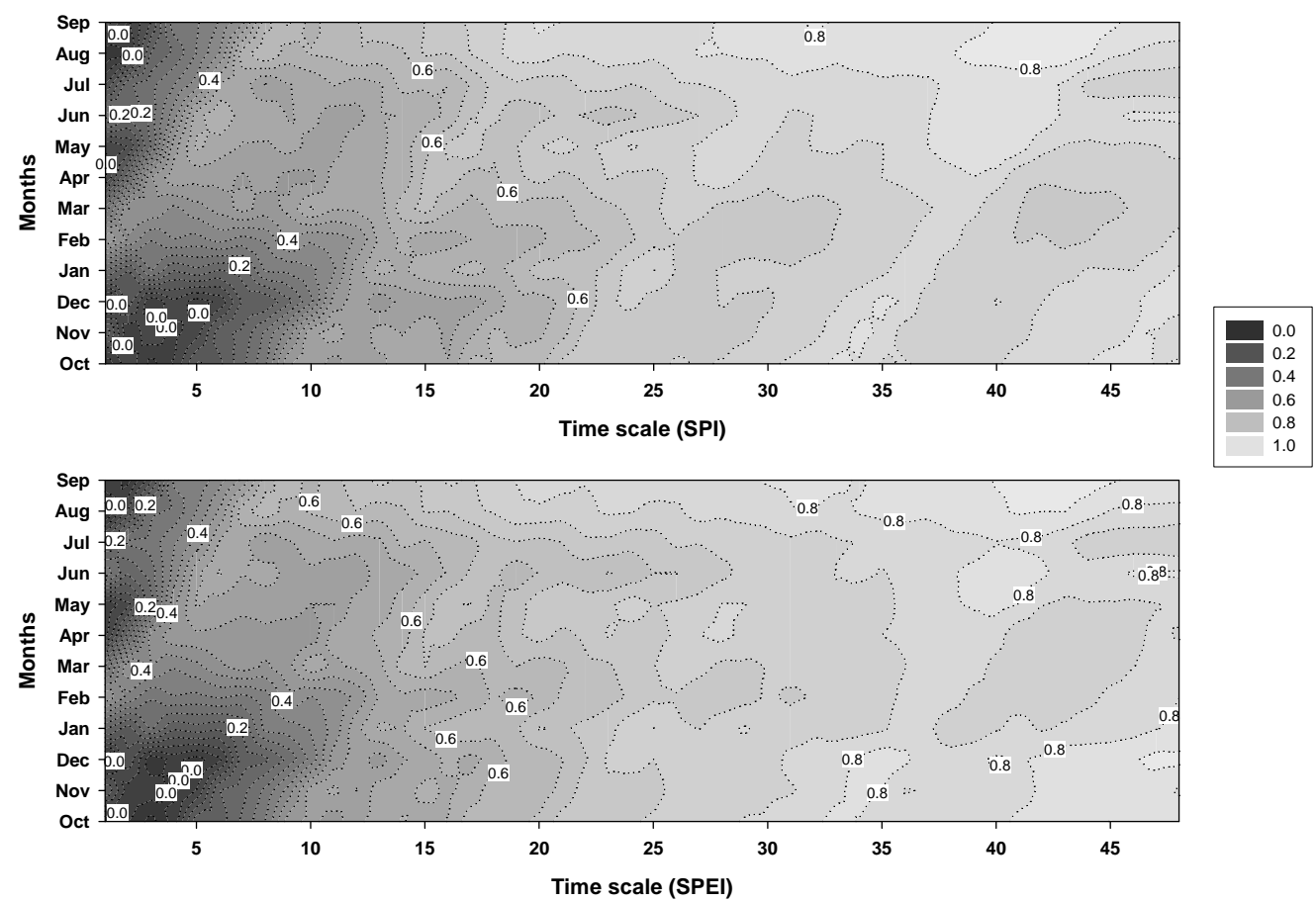

828 Figure 10. Correlation coefficients between the z-standardized monthly outflow series and the 829 monthly SPI and SPEI values at various timescales. Significant correlations $(p<0.05)$ correspond to $\mathrm{R}$ values greater than 0.26 . 

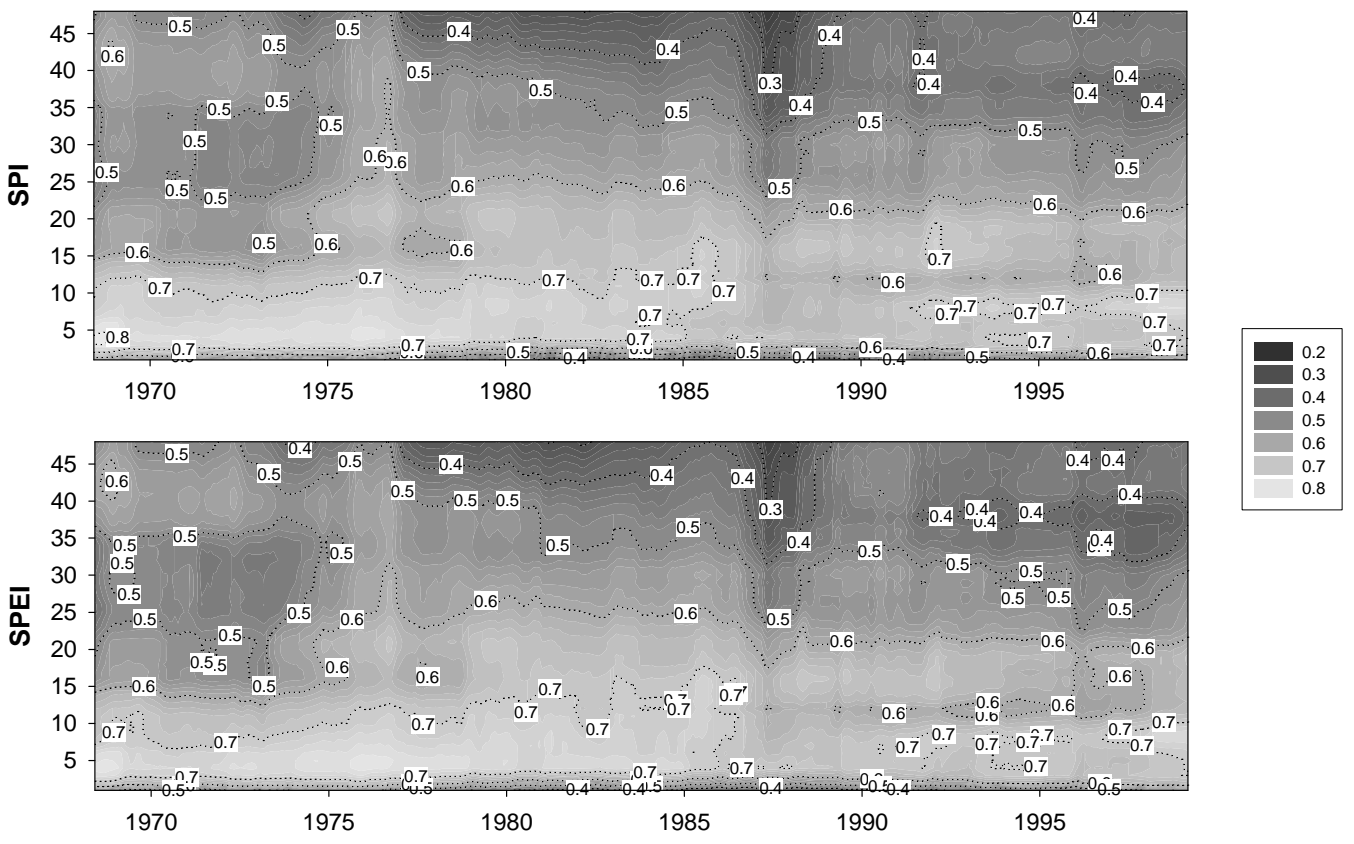

Figure 11. Moving-window Pearson R correlation coefficients between the z-standardized monthly outflow series and the monthly SPI and SPEI values at various timescales. Significant correlations $(p<0.05)$ correspond to $\mathrm{R}$ values greater than 0.51 . 

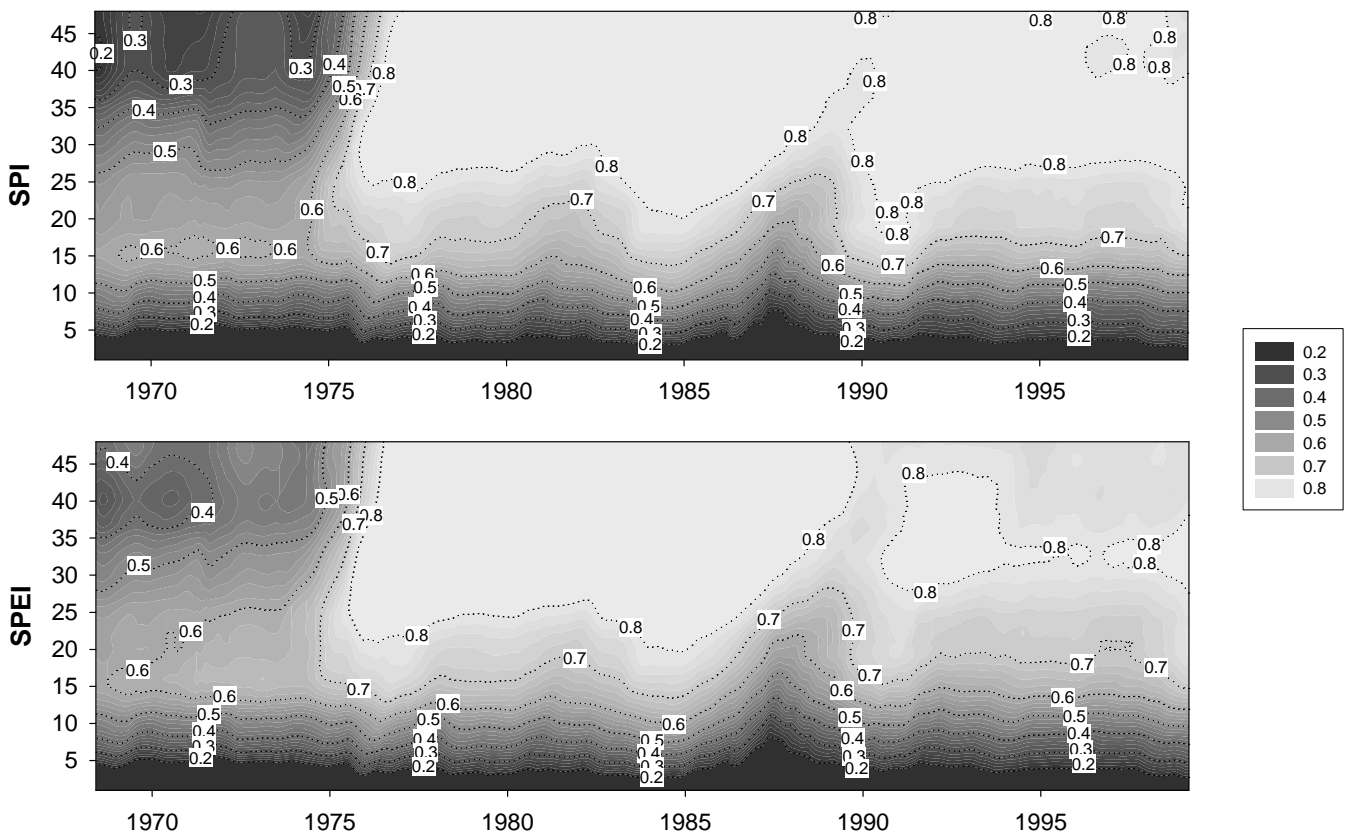

Figure 12. Moving-window R-Pearson correlation coefficients between the z-standardized monthly reservoir storage series and the monthly SPI and SPEI values at various timescales. Significant correlations $(p<0.05)$ correspond to $\mathrm{R}$ values greater than 0.51 . 

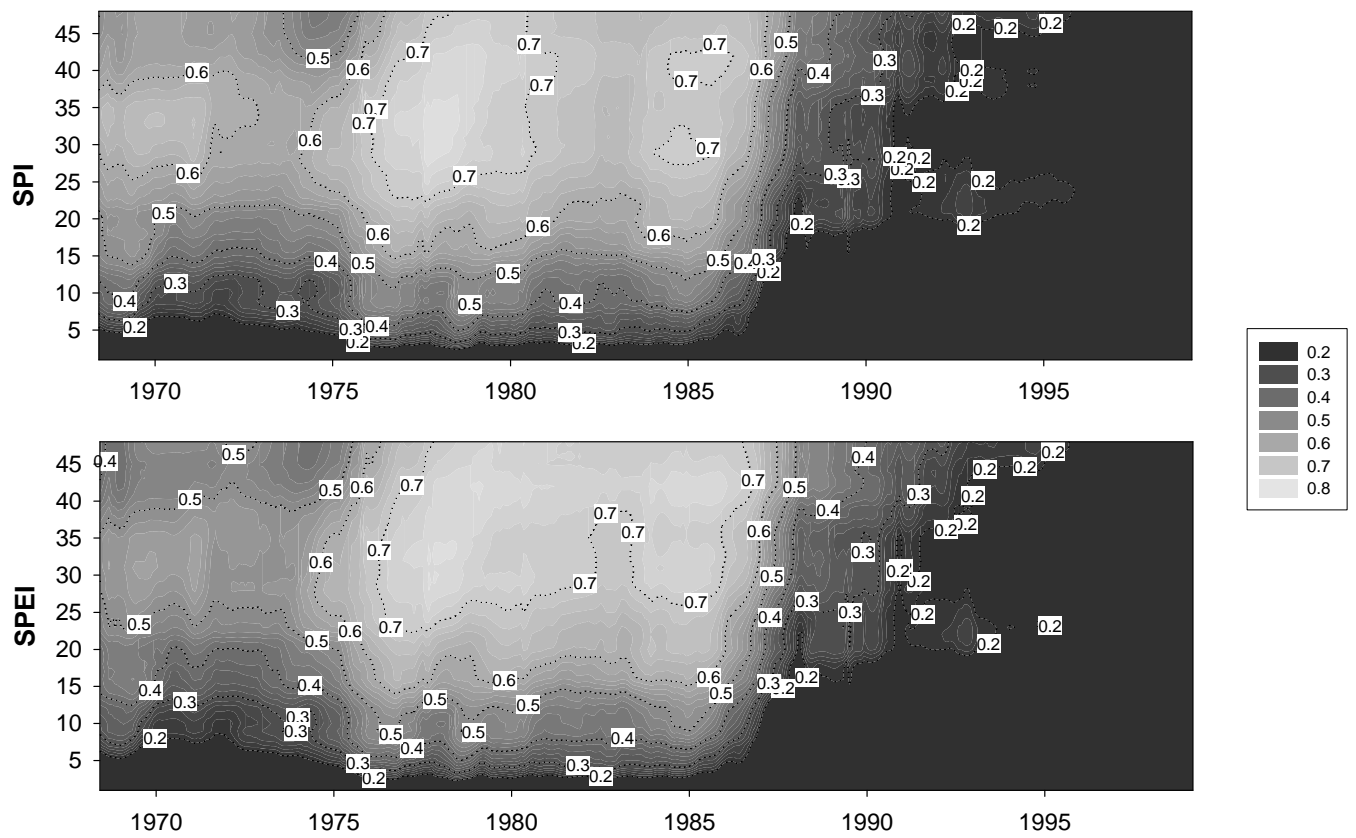

841 Figure 13. Moving-window R-Pearson correlation coefficients between the z-standardized monthly 842 outflow series and the monthly SPI and SPEI values at various timescales. Significant correlations $(p<0.05)$ correspond to $\mathrm{R}$ values greater than 0.51 . 

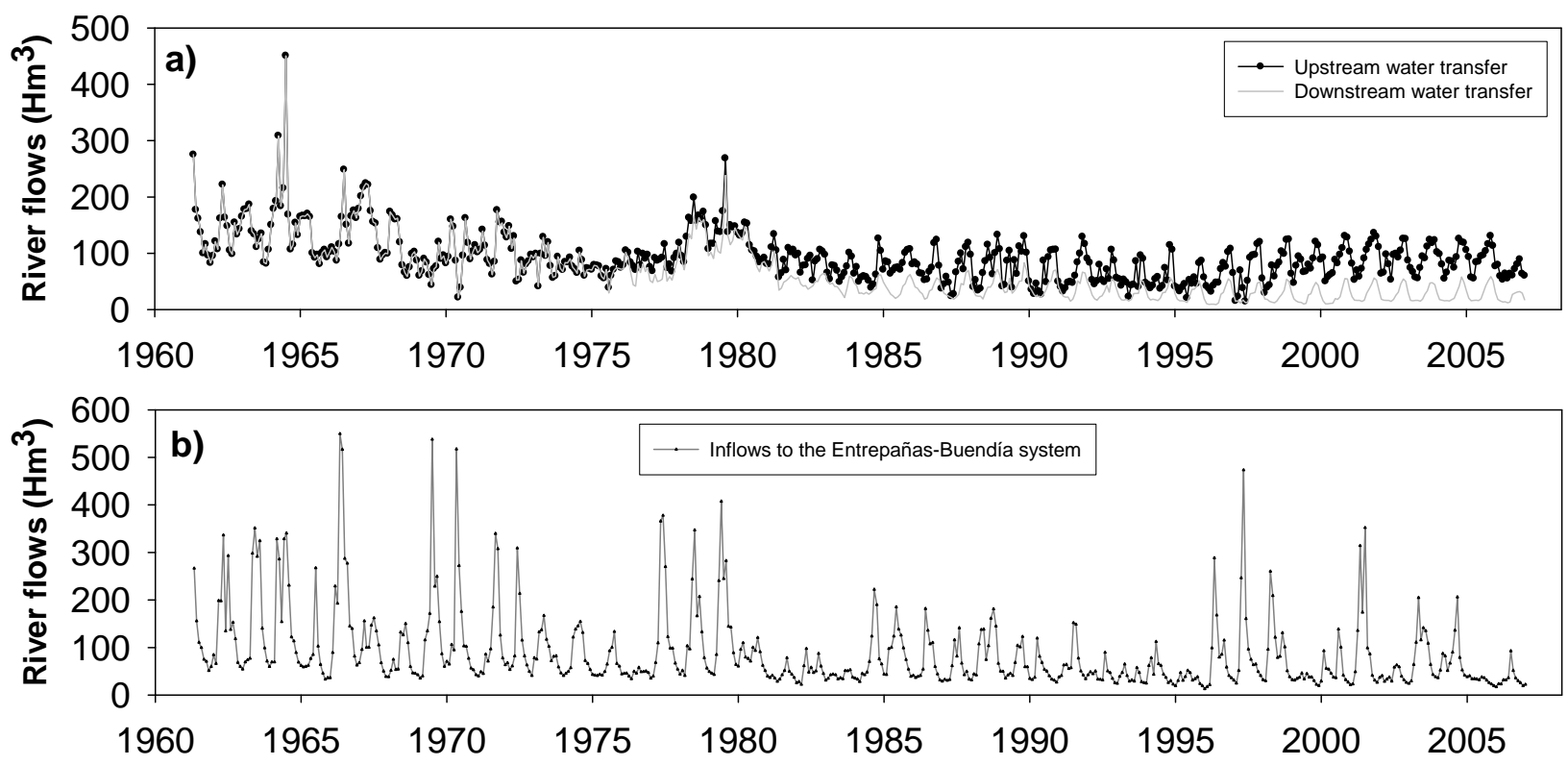

844

845

846

847

848

849

850

851

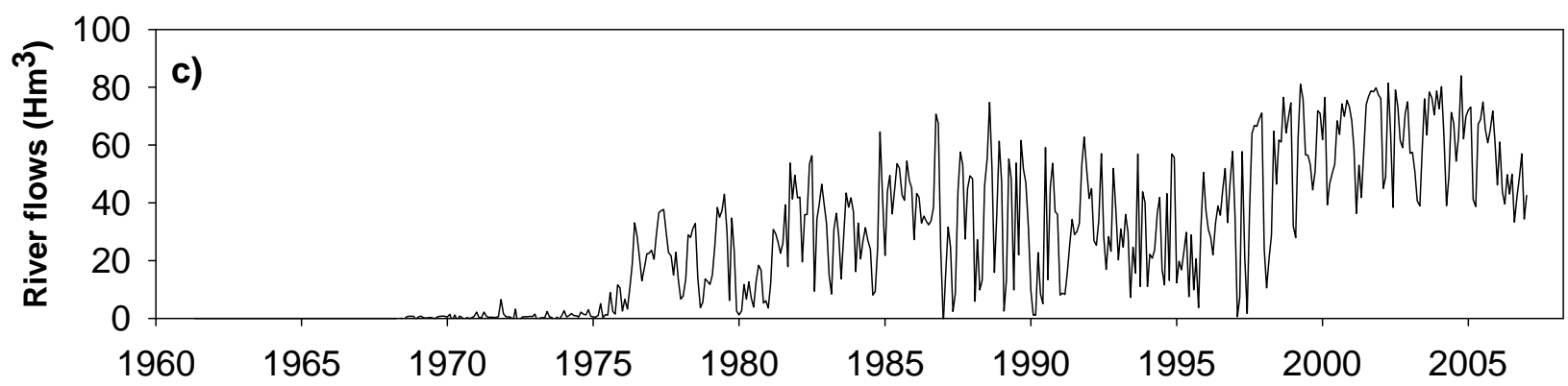

Figure 14. a) Flows in the Tagus River upstream and downstream of the intake point for the water transfer system, b) inflows to the Entrepeñas-Buendía system, and, c) monthly flows for water transfer and irrigation. 